Review article

\title{
Impulsivity and compulsivity in anorexia and bulimia nervosa: A systematic review
}

\author{
Maxine Howard, Eva C. Gregertsen*, Chandni Hindocha, Lucy Serpell \\ Department of Clinical, Educational, and Health Psychology, University College London, London, United Kingdom
}

\section{A R T I C L E I N F O}

\section{Keywords:}

Eating disorders

Action restraint

Risk taking

Action inhibition

Action cancellation

Interference control

Set-shifting

\begin{abstract}
A B S T R A C T
This study aimed to systematically appraise cross-sectional research that compared the cognitive performance of individuals in the acute phase of BN and/or AN to HCs on measures of impulsivity and compulsivity. The results of the systematic review showed support for the trans-diagnostic approach to eating disorders. There was no strong evidence to support the characterisation of AN as high in compulsivity (and low in impulsivity), nor to support the characterisation of BN as high in impulsivity (and low in compulsivity). There appeared to be mixed findings for both impulsivity and compulsivity across AN and BN. Results were highly variable due to the heterogeneous tasks used, and lack of replication across studies. There was no consensus amongst the included studies on the most appropriate task and/or outcome measures that should be used to study the constructs of impulsivity and compulsivity.
\end{abstract}

\section{Introduction}

Anorexia nervosa (AN) and bulimia nervosa (BN) are chronic and disabling illnesses, associated with medical complications, mortality and reduced quality of life (Ágh et al., 2016). Klump et al. (2009) have highlighted the need for effective treatment to avoid the serious consequences associated with a diagnosis of an eating disorder (ED). However, the development of effective treatments is hindered by an incomplete understanding of these illnesses (Fairburn et al., 2003).

\subsection{Diagnoses of anorexia and bulimia nervosa}

Diagnostic classification of an ED is currently based on observable or self-reported phenotypes. Although this can be an effective method of communicating clinical information (First et al., 2004), it fails to take into account genetic and developmental factors, which could influence illness progression (Treasure et al., 2007). Interestingly, of those that have been diagnosed with AN, 55\% go on to develop binge-purge symptoms (Eddy et al., 2008), and almost 30\% of individuals with BN report a history of AN (Keel, 1997), demonstrating shifts between diagnostic categories and symptom fluctuation over time (Fairburn et al., 2003).

As such, recent research has shifted away from these unstable diagnostic categories (Anderluh et al., 2003) and towards neurocognition (Roberts et al., 2003). Examining brain-behaviour relationships could lead to a better understanding of EDs as the symptoms are thought to be underpinned by alterations in cognitive functioning (Tchanturia et al., 2012), and can therefore be better targeted in treatment.

\subsection{Cognitive processing in anorexia nervosa}

Researchers have often made comparisons between the clinical features of AN, such as rigidity in eating behaviour, and Obsessive Compulsive Disorder (OCD) (Serpell et al., 2006, 2002; Tyagi et al., 2015). Individuals with a lifetime history of AN score higher on measures of compulsivity than healthy controls (HCs) (Holliday et al., 2006), as well as retrospectively report the presence of obsessivecompulsive features prior to the onset of AN (Brecelj-Anderluh et al., 2003). Indeed, anxiety disorder symptoms, that may underpin both AN and OCD, predict ED symptoms and diagnosis in later adolescence (Schaumberg et al., 2019) Treasure et al. (2007) suggests that these obsessive-compulsive behaviours are underpinned by trait alterations in cognitive functioning and information processing styles that could be considered candidate endophenotypes.

\subsection{Endophenotypes in eating disorder research}

Endophenotypes reflect heritable enduring characteristics, independent of the state of the individual. Therefore, the characteristic will be present both prior to the development of the illness, after

\footnotetext{
* Corresponding author.

E-mail address: eva.gregertsen.15@ucl.ac.uk (E.C. Gregertsen).
} 
recovery, and be more likely to be found in non-affected family members (Gottesman and Gould, 2003). Treasure et al. (2007) have recommended the use of endophenotypes to diagnose and guide treatment recommendations in the field of EDs.

Research examining endophenotypes in AN is more advanced compared to $\mathrm{BN}$, and has identified cognitive inflexibility as a potential candidate. Individuals with AN are commonly shown to be rigid in behaviour and thinking style, perseverative, and inflexible, when compared to healthy controls (Vitousek and Manke, 1994). Specifically, research has identified difficulties in set shifting - the ability to move back and forth between different stimuli, or 'mental' sets (Holliday et al., 2005). This index of cognitive inflexibility has been observed in those recovered from $\mathrm{AN}$, and to some extent, BN (Roberts et al., 2007, 2010), in addition to unaffected sisters of those with AN (Holliday et al., 2005).

A further aspect of executive functioning that has been suggested as a potential endophenotype is central coherence. Weak central coherence reflects a bias towards detailed processing at the expensive of global processing (Happe and Frith, 2006). Lopez et al. (2008a) describes individuals with AN and BN as having poorer performance on tasks measuring central coherence. In addition, Lopez et al. (2008b) reported superior detailed processing in those with AN. However, the extent to which this represents a distinct endophenotype not related to the state of the illness has been debated (Lopez et al., 2008b; Talbot et al., 2015).

\subsection{Compulsivity in anorexia nervosa}

Evidence of decreased cognitive flexibility (Roberts et al., 2007) and disrupted decision making (Lopez et al., 2008a) has led to the conceptualisation of AN as compulsive in nature (Godier and Park, 2014). Compulsive food restriction and exercise is a key feature of AN (Dalle et al., 2008). However, the definition of compulsivity does not incorporate deficits in central coherence. Rather, compulsivity has been defined as 'actions inappropriate to the situation which persist, have no obvious relationship to the overall goal, and which often result in undesirable consequences' (Dalley et al., 2011). Dysregulation of the systems that mediate compulsivity results in negative consequences, or task impairment, and is reflected in perseverative errors and an inability to switch sets. The compulsive actions performed by individuals with AN are often repetitive and stereotyped. During the course of AN, the behavioural repertoire narrows and compulsive behaviour, such as ritualistic eating and exercise, become more apparent and problematic (Godier and Park, 2014), suggesting that starvation may at least exacerbate compulsivity once the ED is established. This has also been conceptualised as 'over-control' resulting from excessive inhibition, and provided the basis for the development of Radically-Open Dialectical Behaviour Therapy (RO-DBT), for the treatment of AN (Lynch et al., 2013). The term over-control used in RO-DBT describes not just behavioural actions, but can be used to describe features that span behaviour, emotional expression and social connection. Therefore, overcontrol is hypothesised to describe behavioural rigidity that is not receptive to environmental or social feedback, therefore limiting further opportunities to adapt and acts to reinforce perseverative behaviour (Chen et al., 2015).

\subsection{Impulsivity in bulimia nervosa}

Conversely, BN has been described as a disorder of poor impulse control. The loss of control shown during binge eating and purging has been related to an inability to inhibit actions (Boisseau et al., 2009; Claes et al., 2001; Fernandez-Aranda et al., 2009). Evidence comparing $\mathrm{BN}$ and HCs supports this view, showing increased impulsivity in BN compared to non-eating disordered individuals (Claes et al., 2005; Mobbs et al., 2008; Newton et al., 1993; Rosval et al., 2006).

Whilst definitions of impulsivity vary, one classic definition of impulsivity defines it as 'actions which are poorly conceived, prematurely expressed, unduly risky or inappropriate to the situation, and that often result in undesirable consequences' (Daruna and Barnes, 1993). This definition suggests that the construct of impulsivity encompasses behaviour enacted before the individual has sufficiently sampled all available evidence; a deficit inhibiting actions; a tendency to make risky decisions; and a preference for smaller rewards sooner vs. larger rewards later, as described by Evenden (1999). Behaviours that might be categorised as examples of impulsivity according to the definition set out by Daruna and Barnes (1993) have also been described clinically as a problem of 'under-control' by Lynch and colleagues. For example, an episode of binge eating in BN could be thought of as an example of under-control, resulting from poor inhibition of mood-dependent behaviour (Hempel et al., 2018).

It is hoped that the investigation of whether the traits of impulsivity and compulsivity represent distinct endophenotypes that will ultimately aid the identification of individuals at risk, treatment development, and more accurate diagnosis. Research examining the rigid, compulsive nature of AN has already been translated into Cognitive Remediation Therapy (CRT), which targets the behavioural rigidity underpinned by the endophenotype of poor cognitive flexibility. CRT has been shown to enhance the effectiveness of existing treatments, increase quality of life, and reduce eating disorder psychopathology (Dahlgren et al., 2014).

Therapies have also been designed to target impulsivity in individuals with BN, such as DBT (Hill et al., 2011; Safer et al., 2001). There is preliminary evidence that DBT can be effective for BN (Hill et al., 2011; Safer et al., 2001). Although the trait of impulsivity has yet to be established as an endophenotype, understanding the neurocognitive profile of individuals with BN may improve the understanding of treatment outcomes and aetiology (Steiger and Bruce, 2007).

\subsection{The transdiagnostic model of eating disorders}

The existing research base has been taken to indicate that AN and BN are diametrically opposed and lie at either ends of an impulsive/ compulsive spectrum (McCluskey et al., al., 1991). Yet, research has also shown that some elements of impulsivity and compulsivity can cooccur within the same individual. Furthermore, studies of impulsivity and compulsivity in EDs have shown contradictory findings, e.g. elevated impulsivity in AN (Favaro et al., 2005). The transdiagnostic model put forward by Fairburn et al. (2003) suggests that the different eating disorder diagnoses share similar behaviours and underlying maintaining factors, such as the over-evaluation of shape and weight. The transdiagnostic approach proposes that both $\mathrm{AN}$ and $\mathrm{BN}$ share the same basic psychopathology, which is expressed in similar behaviours, such as impulsivity and compulsivity. The frequency with which individuals migrate from one eating disorder diagnosis to another, most often from AN to BN, appears consistent with this view (Agras et al., 2000). Fairburn et al. (2003) claims that, as individuals move from AN to $\mathrm{BN}$, the core psychopathology related to shape and weight remains the same, but as the weight increases, the symptoms of starvation, such as the compulsive rigidity, decrease. The behavioural expression is then in line with that of BN. Therefore, instead of the traditional view of BN as a disorder of impulsivity and AN as a disorder of compulsivity, these constructs may overlap within the same individual (Robbins et al., 2012). Robbins et al. (2012) has recommended that impulsivity and compulsivity should be considered transdiagnostically in order to aid the development of novel treatments. Specifically, they recommended that research should focus on cross-diagnostic behaviours, rather than focusing on specific diagnoses. This is in line with the recent Research Domain Criteria (RDoC) strategy approved and used by the National Institute of Mental Health (NIMH). This strategy outlines the need to focus research on constructs, or behaviours, common across psychiatric disorders, in particular those with neurobiological underpinnings 
(Godier and Park, 2014).

\subsection{Impulsivity and compulsivity across eating disorders}

However, to date, there have been few studies looking at the cooccurrence of impulsivity and compulsivity across EDs. Although research has examined impulsivity in BN, most of these studies have not included individuals with $\mathrm{AN}$, nor have they included measures of compulsivity. Additionally, the extent to which impulsivity and compulsivity may co-occur across $\mathrm{AN}$ and $\mathrm{BN}$ is not known. Therefore, a necessary step before concluding that these constructs represent distinct endophenotypes, associated with each eating disorder, is to synthesise and review the existing evidence, to provide a better understanding of the concepts of impulsivity and compulsivity and their role in AN and BN.

Existing reviews in the area have been limited by focusing solely on $\mathrm{BN}$, examining just impulsivity, or overall neurocognitive profile (Van den Eynde et al., 2011; Waxman, 2009). Meta-analysis across AN and BN have either been limited in scope or out of date (Wu et al., 2013; Zakzanis et al., 2010). An updated and more focused review is clearly warranted, in light of RDoC recommendations and the recent increased interest in neurocognition and the role of possible endophenotypes in EDs.

\subsection{Objective of the present study}

The overall objective of the review is to provide an up to date synthesis of the research on the traits of impulsivity and compulsivity, in $\mathrm{AN}$ and $\mathrm{BN}$, within the same review. A further aim is to examine whether these traits are trans-diagnostic, and observed in both BN and AN. Finally, the review aims to evaluate the extent to which these traits can be considered as potential endophenotypes. Therefore, the review will systematically appraise evidence that compares the cognitive performance on measures of impulsivity and compulsivity, between adults in the acute phase of BN and/or AN, to HCs.

\section{Method}

This review follows guidelines set out by the PRISMA (Preferred Reporting Items for Systematic reviews and Meta-Analysis) statement (Liberati et al., 2009).

\subsection{Literature search}

The electronic databases Pubmed, Medline, and PsychInfo were searched using the following terms: "eating disorder" or "eating disorders" or bulimi* or anorexi*) and (impulsiv* or compulsi* or disinhib* or "loss of control" or persever* or rigid* or "cognitive inflexibility"). All three databases were searched from 2005 to August 2019. A filter was then applied so that only research articles reporting on human subjects were displayed. The reference lists of identified studies and relevant review papers were then examined for any additional references not identified in the electronic search. The breakdown and flow of the search strategy is presented in Fig. 1.

\subsection{Inclusion and exclusion criteria}

Empirical studies that met the following criteria were included: (1) were published in English in a peer reviewed journal; (2) reporting on a behavioural measure of impulsivity or compulsivity; (3) in those aged 18 or above; (4) with a current diagnosis of BN or AN according to DSM-II, -IV, or -V (Diagnostic and Statistical Manual of Mental Disorders) or ICD-9 or -10 (International Statistical Classification of Diseases and Related Health Problems International Classification) criteria; and (4) with a comparison group of $\geq 10$ individuals.

Studies published prior to 2005 were not included to best reflect current methods and definitions. Papers that did not report statistical comparisons between groups were not included. In addition, studies reporting results from individuals with sub-clinical eating disorders, a mixed eating disorder group, or without a formal diagnosis of an eating disorder according to DSM or ICD criteria were excluded. Studies investigating binge eating disorder and EDNOS/OSFED were not included as this was beyond the scope of the current review. Duplicate publications were also excluded from any further analysis.

\subsection{Study selection}

During the first stage of screening the title and abstracts of identified articles were examined according to the a priori defined inclusionand exclusion- criteria. Where this provided insufficient information for assessment against the criteria, stage two involved obtaining and screening full text articles. This was done independently by the first author $(\mathrm{MH})$ and a further rater $(\mathrm{CH})$, with moderate to good inter-rater reliability $(\kappa=0.73)$. Studies for which there were disagreements or uncertain decisions were re-evaluated by the principle investigator (LC)

\subsection{Quality assessment of included studies}

The methodological quality of included studies was assessed according to the STROBE statement. The STROBE checklist consists of 22 items that assess the quality of scientific articles. The checklist was used to calculate the percentage of STROBE criteria met by each article (known as the STROBE score). These scores are presented as part of Table 1 . Overall quality assessment from A-C was used in place of a sum score (Juni et al., 2001). This method has been used in previous reviews (Olmos et al., 2008; Teti et al., 2014). The three categories of global quality assessment were as follows: (A) the study fulfilled more than $80 \%$ of STROBE criteria, (B) the study met between 50 and $80 \%$ of STROBE criteria, or (C) the study met less than $50 \%$ of STROBE criteria.

\subsection{Data synthesis}

The following data from eligible studies was collected: (1) sample sizes, (2) diagnoses of patient sample, (3) type of neurocognitive task used, and (4) mean BMI and standard deviations of each group.

\subsection{Definition of terms}

\subsubsection{Impulsivity}

The term impulsivity has been used to describe a variety of behaviours, and the precise definition of impulsivity remains difficult due to the multi-faceted nature of the concept (Waxman, 2009). Researchers have often investigated a variety of behaviours labelled as impulsive, utilising multiple definitions (Evenden, 1999). Therefore for the purpose of clarity, the definition of impulsivity provided by Daruna and Barnes (1993), wherein impulsivity is defined as 'actions which are poorly conceived, prematurely expressed, unduly risky or inappropriate to the situation and that often result in undesirable consequences' will be used in the current review.

\subsubsection{Compulsivity}

The definition of compulsivity provided by Dalley et al. (2011), wherein compulsivity is defined as 'actions inappropriate to the situation which persist, have no obvious relationship to the overall goal and which often result in undesirable consequences' will be used in the current review, including aspects of compulsivity such as attentional set-shifting, perceptual set-shifting and reversal learning. It is important to note that this definition of compulsivity does not include deficits in central coherence, nor performance on broad measures of executive functioning, as central coherence has been the subject of a recent systematic review (Lang et al., 2014), and the inclusion of broad measures of executive 


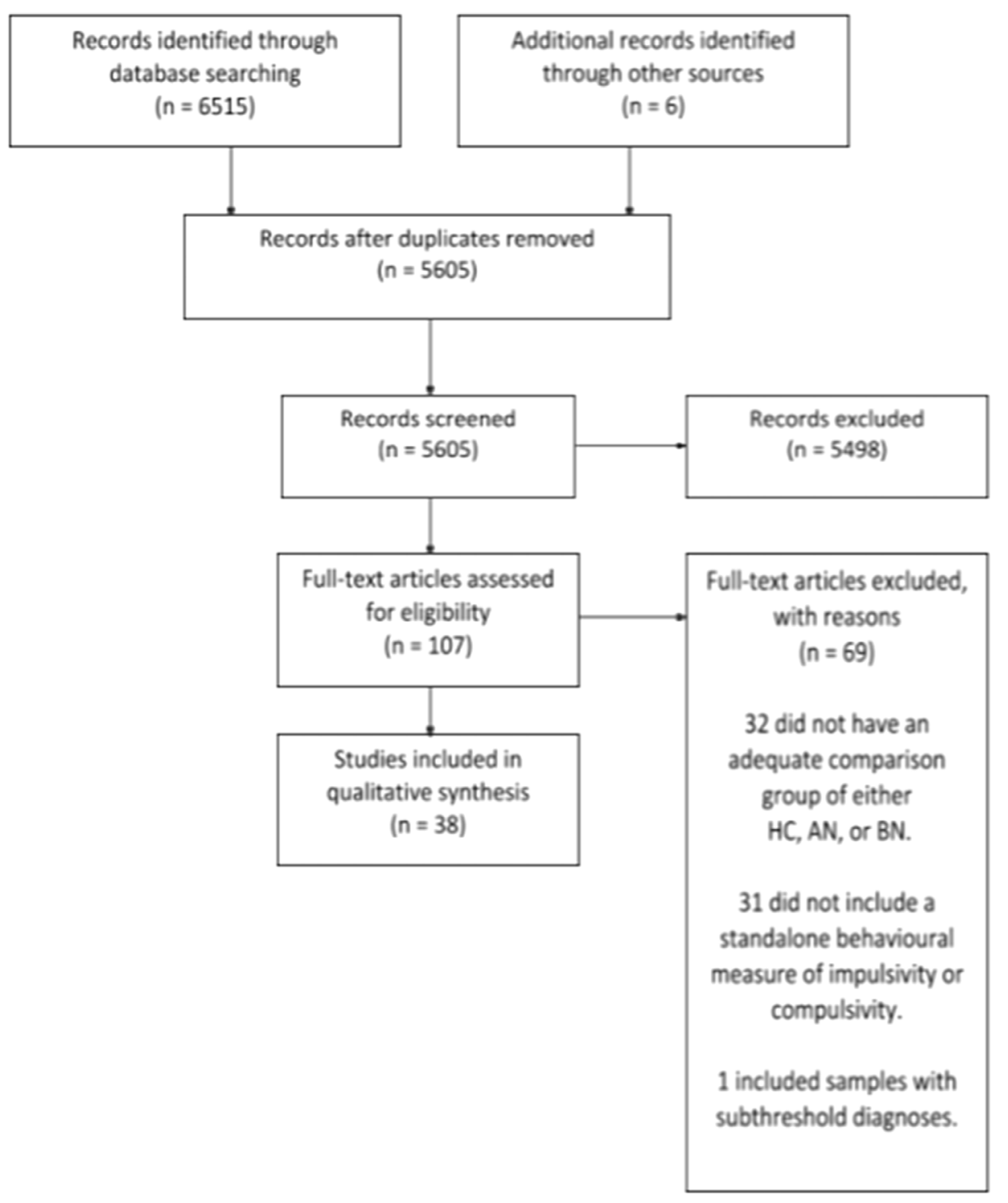

Fig. 1. PRISMA flow diagram.

functioning is beyond the scope of the current review.

\section{Results}

Thirty-eight studies comparing individuals with AN, BN and HCs on measures of impulsivity and/or compulsivity (Table 1) met the inclusion criteria. See Fig 1 for the number of studies included and excluded at each stage of the review. Table 1 provides data on participant characteristics, tasks used, and outcome measures.

The main observations were as follows: (1) Sample sizes tended to be small, and only five out of the 40 studies conducted power calculations to estimate required sample size (Abbate-Daga et al., 2011; Carral-Fernandez et al., 2016; Roberts et al., 2011, 2010; Van den Eynde et al., 2012a). The median size and range for each sample was as follows: $\mathrm{AN}=34(10-215), \mathrm{BN}=26(12-83)$, and HCs $=40(13-$ 216). (2) The outcome measures and methods of assessment varied across studies. (3) The majority of studies $(n=30)$, were conducted in Europe, and all were conducted in first world countries. (Of note, four papers included in this review draw from data from two studies, and are therefore only counted as two studies, as opposed to four.) (4) Studies mainly included only female $(N=35)$ participants. (5) Of the 40 included studies, 16 compared AN to HCs, 9 compared BN to HCs, and 13 studies included comparisons between AN, BN, and HCs. Results are presented separately for the different facets of impulsivity and compulsivity, beginning with a description of the tasks commonly used to measure each facet. This is in line with previous reviews that have reported findings according to different neurocognitive constructs (Duschesne et al., 2004; Zakzanis et al., 2010).

Firstly, the findings for the different neurocognitive domains of impulsivity are presented in the following order: action inhibition, action restraint, action cancelation, interference control/verbal inhibition, risk taking, and planning. Secondly, findings for the different cognitive domains of compulsivity are presented in the following order: attentional set-shifting, perceptual set-shifting, reversal learning, and tasks that measure both attentional set-shifting and reversal learning. Where a task is hypothesised to measure more than one construct, such as the WCST (inhibition and set-shifting), placement in a specific domain is arbitrary and findings should still be considered as applying to more than one construct. See Fig. 2 for a diagram to show the overlapping subcomponents of impulsivity and compulsivity presented in this review (based on Robbins et al. (2012)).

\subsection{Impulsivity}

\subsubsection{Action inhibition}

The term action inhibition describes the prevention of a planned 
Table 1

Summary of studies investigating impulsivity and compulsivity in AN and BN.

\begin{tabular}{|c|c|c|c|c|c|c|c|}
\hline Author \& Date & Country & Participants & Gender & Age & BMI & Neurocognitive Task & $\begin{array}{l}\text { Quality Assessment (STROBE } \\
\text { score }^{\mathrm{b}} \% \text { ) }\end{array}$ \\
\hline Abbate-Daga et al. (2011) & Italy & $\begin{array}{l}\mathrm{AN}-R=30 \\
\mathrm{HC}=30\end{array}$ & $\mathrm{~F}$ & $\begin{array}{l}24.13 \pm 6.16 \\
24.67 \pm 2.64\end{array}$ & $\begin{array}{l}15.62 \pm 1.66 \\
21.04 \pm 2.18\end{array}$ & $\begin{array}{l}\text { WCST }^{1} \\
\text { IGT }^{2} \\
\text { TMT }^{3} \\
\text { HSCT }^{4}\end{array}$ & В $(77 \%)$ \\
\hline Abbate-Daga et al. (2014) & Italy & $\begin{array}{l}\mathrm{AN}=94 \\
\mathrm{HC}=59\end{array}$ & $\mathrm{~F}$ & $\begin{array}{l}24.74 \pm 7.25 \\
25.08 \pm 3.23\end{array}$ & $\begin{array}{l}15.17 \pm 1.98 \\
20.64 \pm 2.01\end{array}$ & WCST $^{1}$ & В $(50 \%)$ \\
\hline Adoue et al. (2015) & France & $\begin{array}{l}\mathrm{AN}=63 \\
\mathrm{HC}=49\end{array}$ & $\mathrm{~F}$ & $\begin{array}{l}30.3 \pm 11.2 \\
24.8 \pm 7.1\end{array}$ & $\begin{array}{l}15.8 \pm 2.0 \\
13.6 \pm 2.3\end{array}$ & $\begin{array}{l}\text { IGT }^{2} \\
\text { BART }^{5} \\
\text { PRLT }^{6}\end{array}$ & B $(68 \%)$ \\
\hline Aloi et al. (2015) & Italy & $\begin{array}{l}\mathrm{AN}=45 \\
\mathrm{HC}=45\end{array}$ & $\mathrm{~F}$ & $\begin{array}{l}22.8 \pm 5.6 \\
25.6 \pm 3.5\end{array}$ & $\begin{array}{l}15.5 \pm 1.4 \\
20.2 \pm 1.6\end{array}$ & $\begin{array}{l}\text { IGT }^{2} \\
\text { TMT }^{3} \\
\text { WCST }^{1} \\
\text { HSCT }^{4}\end{array}$ & B $(63 \%)$ \\
\hline Bartholdy et al. (2017)a & UK & $\begin{array}{l}\mathrm{AN}=28 \\
\mathrm{BN}=27 \\
\mathrm{HC}=28\end{array}$ & $\mathrm{~F}$ & $\begin{array}{l}30.0 \pm 10.51 \\
25.3 \pm 6.85 \\
24.64 \pm 5.14\end{array}$ & $\begin{array}{l}16.55 \pm 1.79 \\
22.57 \pm 3.3 \\
22.04 \pm 2.03\end{array}$ & $\begin{array}{l}\text { Cued Reaction Time Task } \\
\text { SS }^{7}\end{array}$ & В $(73 \%)$ \\
\hline Bartholdy et al. (2017)b & UK & $\begin{array}{l}\mathrm{AN}=28 \\
\mathrm{BN}=27 \\
\mathrm{HC}=28\end{array}$ & $\mathrm{~F}$ & $\begin{array}{l}30.0 \pm 10.51 \\
25.3 \pm 6.85 \\
24.64 \pm 5.14\end{array}$ & $\begin{array}{l}16.55 \pm 1.79 \\
22.57 \pm 3.3 \\
22.04 \pm 2.03\end{array}$ & $\mathrm{TD}^{14}$ & B $(68 \%)$ \\
\hline Boisseau et al. (2012) & USA & $\begin{array}{l}\mathrm{HC}=21 \\
\mathrm{BN}=12\end{array}$ & $\mathrm{~F}$ & $\begin{array}{l}24.24 \pm 3.47 \\
23.48 \pm 4.37\end{array}$ & $\begin{array}{l}22.22 \pm 2.28 \\
22.30 \pm 3.75\end{array}$ & $\mathrm{SS}^{7}$ & C $(40 \%)$ \\
\hline Brand et al. (2007) & Germany & $\begin{array}{l}\mathrm{BN}=14 \\
\mathrm{HC}=14\end{array}$ & $\mathrm{~F}$ & $\begin{array}{l}21.86 \pm 3.30 \\
21.64 \pm 2.90\end{array}$ & $\begin{array}{l}21.57 \pm 3.84 \\
21.33 \pm 2.30\end{array}$ & $\begin{array}{l}\text { GDT }^{8} \\
\text { Colour-Word Interference } \\
\text { TMT }^{3} \\
\text { Nelson's Modified CST } \\
\text { TOL }^{10} \\
\text { ROCFT }^{11}\end{array}$ & B $(63 \%)$ \\
\hline Brogan et al. (2010) & Italy & $\begin{array}{l}\mathrm{HC}=20 \\
\mathrm{AN}=22 \\
\mathrm{BN}=17\end{array}$ & $\mathrm{~F}$ & $\begin{array}{l}27.27 \pm 6.99 \\
29.09 \pm 7.36 \\
29.94 \pm 6.41\end{array}$ & $\begin{array}{l}21.55 \pm 1.42 \\
16.03 \pm 2.04 \\
31.87 \pm 9.42\end{array}$ & $\mathrm{IGT}^{2}$ & В $(59 \%)$ \\
\hline Butler et al. (2005) & UK & $\begin{array}{l}\mathrm{AN}=15 \\
\mathrm{HC}=16\end{array}$ & $\mathrm{~F}$ & $\begin{array}{l}27.9 \pm 9.9 \\
28.4 \pm 8.3\end{array}$ & $\begin{array}{l}\text { Not Reported } \\
22.75\end{array}$ & $\begin{array}{l}\text { Bets-16 } \\
\text { Continuous Performance Test }\end{array}$ & C (45\%) \\
\hline Camacho Ruiz et al. (2008) & Mexico & $\begin{array}{l}\mathrm{BN}=26 \\
\mathrm{AN}=10 \\
\mathrm{HC}=36\end{array}$ & $\mathrm{~F}$ & Not Reported & Not Reported & $\begin{array}{l}\text { WCST }^{1} \\
\text { Stroop } \\
\text { ROCT }^{11} \\
\text { TOL }^{10}\end{array}$ & В $(50 \%)$ \\
\hline Claes et al. (2006) & Germany & $\begin{array}{l}\mathrm{AN}-R=20 \\
\mathrm{AN}-P=14 \\
\mathrm{BN}=22 \\
\mathrm{HC}=83\end{array}$ & $\mathrm{~F}$ & $\begin{array}{l}23.0 \pm 6.6 \\
21.7 \pm 6.8 \\
22.7 \pm 5.8 \\
20.1 \pm 3.1\end{array}$ & Not Reported & Stop-go Task & В $(50 \%)$ \\
\hline Collantoni et al. (2016) & Italy & $\begin{array}{l}\mathrm{AN}=85 \\
\mathrm{HC}=106\end{array}$ & $\mathrm{~F}$ & $\begin{array}{l}22.7 \pm 7.0 \\
23.7 \pm 6.6\end{array}$ & $\begin{array}{l}15.9 \pm 1.5 \\
21.5 \pm 3.2\end{array}$ & $\mathrm{SS}^{7}$ & B $(71 \%)$ \\
\hline Danner et al. (2012) & Netherlands & $\begin{array}{l}\mathrm{AN}=16 \\
\mathrm{HC}=15\end{array}$ & $\mathrm{~F}$ & $\begin{array}{l}25.63 \pm 5.41 \\
25.80 \pm 4.69\end{array}$ & $\begin{array}{l}14.65 \pm 1.7 \\
21.46 \pm 2.29\end{array}$ & $\begin{array}{l}\text { Bergs CST } \\
\text { ROCFT }^{11} \\
\text { IGT }^{2}\end{array}$ & B $(54 \%)$ \\
\hline Fagundo et al. (2012) & Spain & $\begin{array}{l}\mathrm{AN}=35 \\
\mathrm{HC}=137\end{array}$ & $\mathrm{~F}$ & $\begin{array}{l}28.1 \pm 8.2 \\
24.8 \pm 7.0\end{array}$ & $\begin{array}{l}17.2 \pm 1.4 \\
21.5 \pm 2.7\end{array}$ & $\begin{array}{l}\text { Stroop } \\
\text { IGT }^{2} \\
\text { WCST }^{1}\end{array}$ & B $(63 \%)$ \\
\hline Galderisi et al. (2011) & Italy & $\begin{array}{l}\mathrm{BN}=83 \\
\mathrm{HC}=77\end{array}$ & $\mathrm{~F}$ & $\begin{array}{l}24.0 \pm 4.3 \\
23.8 \pm 3.4\end{array}$ & $\begin{array}{l}21.5 \pm 3.7 \\
21.5 \pm 2.6\end{array}$ & WCST $^{1}$ & B $(63 \%)$ \\
\hline Galimberti et al. (2012) & Italy & $\begin{array}{l}\mathrm{AN}-R=24 \\
\mathrm{AN}-B=12 \\
\mathrm{BN}=16 \\
\mathrm{HC}=40\end{array}$ & $\mathrm{~F}$ & $\begin{array}{l}26.70 \pm 9.58 \\
27.08 \pm 8.86 \\
25.31 \pm 5.79 \\
25.95 \pm 8.41\end{array}$ & $\begin{array}{l}14.26 \pm 1.21 \\
15.05 \pm 1.55 \\
20.43 \pm 3.65 \\
19.21 \pm 1.57\end{array}$ & $\begin{array}{l}\text { SS }^{7} \\
\text { ID-ED Set Shifting }\end{array}$ & В $(59 \%)$ \\
\hline Holliday et al. (2005) & UK & $\begin{array}{l}\mathrm{AN}=47 \\
\mathrm{HC}=47\end{array}$ & $\mathrm{~F}$ & $\begin{array}{l}26.3 \pm 10.2 \\
26.5 \pm 6.1\end{array}$ & $\begin{array}{l}17.9 \pm 2.7 \\
22.1 \pm 2.3\end{array}$ & $\mathrm{TMT}^{3}$ & Cat Bat Task B (72\%) \\
\hline Kekic et al. (2016) & UK & $\begin{array}{l}\mathrm{BN}=39 \\
\mathrm{HC}=53\end{array}$ & Mixed & $\begin{array}{l}25.85 \pm 6.62 \\
25.55 \pm 7.33\end{array}$ & $\begin{array}{l}21.65 \pm 3.2 \\
21.71 \pm 2.17\end{array}$ & $\mathrm{TD}^{14}$ & B $(68 \%)$ \\
\hline Kemps and Wilsdon, 2010 & Australia & $\begin{array}{l}\mathrm{BN}=13 \\
\mathrm{HC}=13\end{array}$ & $\mathrm{~F}$ & $\begin{array}{l}22.17 \pm 3.88 \\
20.76 \pm 3.39\end{array}$ & $\begin{array}{l}23.61 \pm 2.61 \\
22.42 \pm 3.35\end{array}$ & $\begin{array}{l}\text { Stroop } \\
\text { HSCT }^{4} \\
\text { MFFT }^{13}\end{array}$ & C $(45 \%)$ \\
\hline Lee et al. (2017) & Korea & $\begin{array}{l}\mathrm{BN}=13 \\
\mathrm{HC}=14\end{array}$ & $\mathrm{~F}$ & $\begin{array}{l}23.7 \pm 2.2 \\
23.3 \pm 2.2\end{array}$ & $\begin{array}{l}21.5 \pm 2.2 \\
20.4 \pm 2.6\end{array}$ & Stroop & B $(66 \%)$ \\
\hline Liao et al. (2009) & UK & $\begin{array}{l}\mathrm{BN}=26 \\
\mathrm{HC}=51 \\
\mathrm{AN}=29\end{array}$ & $\mathrm{~F}$ & $\begin{array}{l}27.8 \pm 6.1 \\
29.4 \pm 9.6 \\
28.5 \pm 9.17\end{array}$ & $\begin{array}{l}25.3 \pm 4.7 \\
23.1 \pm 3.9 \\
15.5 \pm 1.3\end{array}$ & IGT $^{2}$ & B $(54 \%)$ \\
\hline Lopez et al. (2008) & UK & $\begin{array}{l}\mathrm{BN}=42 \\
\mathrm{HC}=42 \\
\mathrm{AN}=42\end{array}$ & $\mathrm{~F}$ & $\begin{array}{l}27.0 \pm 7.2 \\
26.3 \pm 6.4\end{array}$ & $\begin{array}{l}21.7 \pm 2.4 \\
21.9 \pm 2.7\end{array}$ & ROCFT $^{11}$ & B $(72 \%)$ \\
\hline Marsh et al. (2009) & USA & $\begin{array}{l}\mathrm{BN}=20 \\
\mathrm{HC}=20\end{array}$ & $\mathrm{~F}$ & $\begin{array}{l}25.7 \pm 7.0 \\
26.35 \pm 5.7\end{array}$ & $\begin{array}{l}22.92 \pm 2.3 \\
22.24 \pm 2.2\end{array}$ & Simon Spatial Incompatibility Task & B $(77 \%)$ \\
\hline Mobbs et al. (2008) & Switzerland & $\begin{array}{l}\mathrm{BN}=18 \\
\mathrm{HC}=18\end{array}$ & $\mathrm{~F}$ & $\begin{array}{l}25.11 \pm 3.88 \\
24.28 \pm 3.36\end{array}$ & $\begin{array}{l}20.38 \pm 2.61 \\
21.02 \pm 1.64\end{array}$ & Affective Shifting Task & B $(63 \%)$ \\
\hline
\end{tabular}


Table 1 (continued)

\begin{tabular}{|c|c|c|c|c|c|c|c|}
\hline Author \& Date & Country & Participants & Gender & Age & BMI & Neurocognitive Task & $\begin{array}{l}\text { Quality Assessment (STROBE } \\
\text { score }^{\mathrm{b}} \% \text { ) }\end{array}$ \\
\hline Nakazato et al. (2009) & UK & $\begin{array}{l}\mathrm{AN}=29 \\
\mathrm{HC}=28\end{array}$ & $\mathrm{~F}$ & $\begin{array}{l}28.3 \pm 11.0 \\
26.9 \pm 5.8\end{array}$ & $\begin{array}{l}15.6 \pm 1.6 \\
22.3 \pm 2.5\end{array}$ & WCST $^{1}$ & B $(68 \%)$ \\
\hline Pignatti et al. (2013) & Italy & $\begin{array}{l}\mathrm{AN}=23 \\
\mathrm{BN}=17 \\
\mathrm{HC}=20\end{array}$ & $\mathrm{~F}$ & $\begin{array}{l}29.1 \pm 7.4 \\
29.9 \pm 6.4 \\
27.8 \pm 7.0\end{array}$ & $\begin{array}{l}16.0 \pm 2.0 \\
31.9 \pm 9.4 \\
21.6 \pm 1.6\end{array}$ & $\begin{array}{l}\text { HSCT }^{4} \\
\text { TMT }^{3} \\
\text { WCST }^{1}\end{array}$ & B $(50 \%)$ \\
\hline Roberts et al. (2010) & UK & $\begin{array}{l}\text { ANR }=35 \\
\text { ANBP }=33 \\
\text { BN }=30 \\
\mathrm{HC}=88\end{array}$ & $\mathrm{~F}$ & $\begin{array}{l}23.71 \pm 6.39 \\
25.58 \pm 7.64 \\
26.43 \pm 6.84 \\
28.43 \pm 8.47\end{array}$ & $\begin{array}{l}17.98 \pm 2.18 \\
17.88 \pm 3.0 \\
21.66 \pm 2.94 \\
22.07 \pm 1.79\end{array}$ & $\begin{array}{l}\text { TMT }^{3} \\
\text { WCST }^{1} \\
\text { Brixton } \\
\text { Haptic Illusions }\end{array}$ & B $(72 \%)$ \\
\hline Roberts et al. (2011) & UK & $\begin{array}{l}\mathrm{AN}=35 \\
\mathrm{AN}-B=33 \\
\mathrm{BN}=30 \\
\mathrm{HC}=88\end{array}$ & $\mathrm{~F}$ & $\begin{array}{l}23.71 \pm 6.39 \\
25.58 \pm 7.64 \\
26.43 \pm 6.84 \\
28.43 \pm 8.43\end{array}$ & $\begin{array}{l}17.98 \pm 2.18 \\
17.88 \pm 3.00 \\
21.66 \pm 2.94 \\
22.07 \pm 1.79\end{array}$ & $\begin{array}{l}\text { Group Embedded Fig. Test } \\
\text { ROCFT }^{11}\end{array}$ & B $(63 \%)$ \\
\hline Rosval et al. (2006) & Canada & $\begin{array}{l}\mathrm{BN}=79 \\
\mathrm{ANBP}=17 \\
\mathrm{ANR}=18 \\
\mathrm{HC}=59\end{array}$ & $\mathrm{~F}$ & $\begin{array}{l}25.04 \pm 6.42 \\
25.59 \pm 7.71 \\
24.56 \pm 10.21 \\
24.32 \pm 6.19\end{array}$ & $\begin{array}{l}21.30 \pm 1.91 \\
16.66 \pm 1.67 \\
17.13 \pm 1.52 \\
21.93 \pm 2.22\end{array}$ & Go/No-Go Task & C $(36 \%)$ \\
\hline Sherman et al. (2006) & USA & $\begin{array}{l}\mathrm{AN}=18 \\
\mathrm{HC}=19\end{array}$ & $\mathrm{~F}$ & $\begin{array}{l}25.56 \pm 5.8 \\
25.68 \pm 5.3\end{array}$ & $\begin{array}{l}16.68 \pm 1.1 \\
22.22 \pm 1.8\end{array}$ & ROCFT $^{11}$ & В $(63 \%)$ \\
\hline Southgate et al., 2008 & UK & $\begin{array}{l}\mathrm{HC}=26 \\
\mathrm{AN}=20 \\
\mathrm{BN}=14\end{array}$ & $\mathrm{~F}$ & $\begin{array}{l}27.27 \pm 11.52 \\
26.80 \pm 8.49 \\
25.71 \pm 4.94\end{array}$ & $\begin{array}{l}21.95 \pm 3.42 \\
16.31 \pm 2.64 \\
21.12 \pm 6.67\end{array}$ & $\mathrm{MFFT}^{13}$ & B $(68 \%)$ \\
\hline Steward et al. (2017) & Spain & $\begin{array}{l}\mathrm{AN}-R=37 \\
\mathrm{AN}-\mathrm{BP}=19 \\
\mathrm{HC}=80\end{array}$ & $\mathrm{~F}$ & $\begin{array}{l}23.4 \pm 7.22 \\
28.6 \pm 6.56 \\
23.0 \pm 4.43\end{array}$ & $\begin{array}{l}16.15 \pm 1.83 \\
16.65+0.88 \\
21.62 \pm 3.22\end{array}$ & $\begin{array}{l}\text { Paper-and-pencil monetary choice } \\
\text { task }\end{array}$ & В $(70 \%)$ \\
\hline Talbot et al. (2015) & Australia & $\begin{array}{l}\mathrm{AN}=24 \\
\mathrm{HC}=43\end{array}$ & Mixed & $\begin{array}{l}21.0 \\
21.5\end{array}$ & $\begin{array}{l}14.99 \pm 1.83 \\
21.81 \pm 1.48\end{array}$ & $\begin{array}{l}\text { ROCFT }^{11} \\
\text { MFFT }^{13} \\
\text { WCST }^{1}\end{array}$ & B (54\%) \\
\hline Tchanturia et al., 2012a & UK & $\begin{array}{l}\mathrm{AN}=171 \\
\mathrm{BN}=82 \\
\mathrm{HC}=199\end{array}$ & $\mathrm{~F}$ & $\begin{array}{l}25.4 \pm 8.2 \\
27.3 \pm 8.3 \\
27.7 \pm 8.8\end{array}$ & $\begin{array}{l}15.2 \pm 1.9 \\
21.3 \pm 2.4 \\
21.9 \pm 1.9\end{array}$ & WCST $^{1}$ & B $(68 \%)$ \\
\hline Tchanturia et al. (2011) & UK & $\begin{array}{l}\mathrm{HC}=216 \\
\mathrm{AN}=215 \\
\mathrm{BN}=69\end{array}$ & $\mathrm{~F}$ & $\begin{array}{l}27.0 \pm 7.9 \\
26.9 \pm 8.2 \\
27.7 \pm 7.8\end{array}$ & $\begin{array}{l}21.9 \pm 1.8 \\
15.0 \pm 1.7 \\
21.0 \pm 2.1\end{array}$ & Brixton & A $(81 \%)$ \\
\hline Tchanturia et al., 2012b & UK \& Spain & $\begin{array}{l}\mathrm{AN}=19 \\
\mathrm{AN}=29 \\
\mathrm{HC}=20 \\
\mathrm{HC}=41\end{array}$ & $\begin{array}{l}M \\
F \\
M \\
F\end{array}$ & $\begin{array}{l}27.22 \pm 8.54 \\
27.52 \pm 7.49 \\
25.42 \pm 7.63 \\
22.2 \pm 5.68\end{array}$ & $\begin{array}{l}17.49 \pm 2.64 \\
16.59 \pm 1.20 \\
23.54 \pm 3.78 \\
22.1 \pm 3.94\end{array}$ & $\mathrm{IGT}^{2}$ & B $(68 \%)$ \\
\hline Van den Eynde et al. (2011) & UK & $\begin{array}{l}\mathrm{HC}=65 \\
\mathrm{BN}=40\end{array}$ & $\mathrm{~F}$ & $\begin{array}{l}24.0 \pm 2.6 \\
28.3 \pm 8.1\end{array}$ & $\begin{array}{l}22.2 \pm 3.3 \\
25.2 \pm 7.2\end{array}$ & $\begin{array}{l}\text { Stroop } \\
\text { Go/No-Go } \\
\text { GDT }^{8}\end{array}$ & В $(63 \%)$ \\
\hline
\end{tabular}

Task abbreviations:.

1 Wisconsin Card Sorting Task,.

2 Iowa Gambling Task,.

3 Trail Making Task,

4 Hayling Sentence Completion Task,.

5 Balloon Analogue Risk Task,.

6 Probabilistic Reversal Learning Task,.

7 Stop Signal Task,.

8 Game of Dice Task,.

9 Nelsons Modified Card Sorting Task,.

${ }^{10}$ Tower of London/Hanoi,.

11 Rey-Osterrieth Complex Figures Task,.

12 Bergs Card Sorting Task,.

13 Matching Familiar Figures Test,.

14 Temporal Discounting Task.

a Strengthening the Reporting of Observational Studies in Epidemiology.

b Scale of A-C.

physical response, and a deficit in this ability has been used as a behavioural estimate of impulsivity (Eagle et al., 2008). This process has been measured using a variety of behavioural tasks, such as the Go/ NoGo task and the Stop Signal Reaction Time Task, (Logan, 1994). However, these tasks can be used to measure a variety of outcomes (such as errors and response times to different targets), which have been used as evidence of slightly different sub-constructs of action inhibition, (Dalley et al., 2011). Schachar et al. (2007) differentiated between action restraint; the ability to withhold a response tendency, and action cancellation; the ability to cancel a pre-planned action.
Studies investigating the different components of inhibition are discussed separately below.

\subsubsection{Action restraint}

The Go/NoGo task assesses the capacity for stimulus discrimination and action restraint. Participants are told that there will be a series of rapidly presented stimuli, which will either be target items or distractors. Participants are required to manually respond to target words, and withhold responses to distractor stimuli (Murphy et al., 1999). The outcome measures from this task are the time taken to respond 


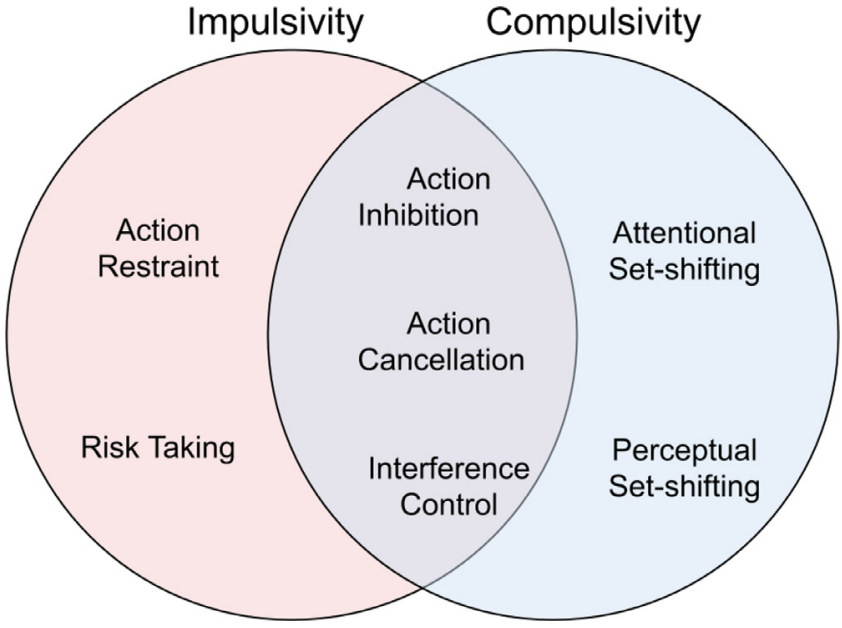

Fig. 2. Diagram to illustrate the overlapping constructs of impulsivity and compulsivity. Adapted from Robbins et al. (2012).

(response times), incorrect responses to distractor stimuli (commission errors), and failures to appropriately respond to target stimuli (omission errors). Commission errors are hypothesised to be maximally sensitive to deficits of action restraint (Rosval et al., 2006).

Two studies have used the Go/NoGo task to assess problems of action restraint. One study used a Go/NoGo task with monetary reward and punishment (Bruce et al., 2003; Rosval et al., 2006), and one without (Van den Eynde et al., 2012b). Both studies showed no differences between groups on errors of omission. Van den Eynde et al. (2012b) showed no differences between individuals with BN compared to $\mathrm{HC}$ on total commission errors, indicating no difference in action restraint. Similarly, Rosval et al. (2006) demonstrated no differences between groups (AN, BN \& HC) for total commission errors.

Another variant of the Go/NoGo task that measures action restraint is the Affective Shifting task (AFT). The AFT differs from the Go/NoGo task as the block order is arranged to provide an additional measure of flexibility in shifting from responding to one set of instructions, versus another. In addition, affective or personally relevant stimuli (such as food or body words) are used to examine any potential attentional biases. Therefore the outcome measures assess both action restraint and interference control. Only one study examined the difference between individuals with BN and HC using the AFT (Mobbs et al., 2008). In this particular version of the AFT, food and body words were used as stimuli. Overall there were no group differences between BN and HCs for total RTs, or for either body or food RTs. However, individuals with BN had lower discrimination ability, showing a lower proportion of hits to false alarms, but an overall higher number of hits and false alarms, indicating a difficulty with action restraint. Specifically, individuals with BN had a higher number of hits and false alarms for food words only, suggesting a food specific action restraint impairment. No other significant between group differences were found, including measures of interference control/shifting ability.

\subsubsection{Action cancellation}

The Stop Signal Task (SST) largely assesses action cancellation. During this task, participants are instructed to respond as quickly as possible to a reaction time task. However, on a percentage of trials the participant is instructed to cancel a response, by the sounding of a 'stop signal'. The time taken to stop the response is termed the Stop Signal Reaction Time (SSRT), which provides a measure of action cancellation. Other outcome measures include mean RTs for correct 'go' trials, and total errors on 'go' trials. Five studies used the SST to examine differences in action cancellation between groups (Bartholdy et al., 2017; Boisseau et al., 2012; Claes et al., 2006; Collantoni et al., 2016; Galimberti et al., 2012). Galimberti et al. (2012) used the SST to look at differences between individuals with AN-Re, AN-Be, BN, and HCs. Overall both AN-Be, and AN-Re groups displayed increased SSRTs compared to HC. There were no differences between groups for mean RTs for correct 'go' trials. Moreover Bartholdy et al. (2017), who compared AN and HC groups, found that the AN group showed the greatest stop accuracy, as well as the slowest RT on go trials. Similarly, Collantoni et al. (2016), comparing HCs with both a weight-restored and underweight AN sample, found that the underweight AN patients demonstrated significantly longer RT than healthy women and weightrecovered patients. Conversely, Claes et al. (2006) found no difference between AN-R, AN-P, BN and HC groups for any of the SST outcome measures. This is in line with findings from Boisseau et al. (2012) who also found no evidence of impaired action cancellation in those with BN compared to HCs.

\subsubsection{Inference control/verbal inhibition}

Interference control is another form of cognitive control, which is similar to inhibition, but requires the suppression of a competing distractor stimulus, whilst simultaneously initiating an alternative response (Nigg, 2000). Measures of interference control used in the included studies of the current review (see Table 1) include the Stroop test, Hayling Sentence Completion Test, and the Simon Spatial Incompatibility Task. These tasks are discussed in turn below.

3.1.4.1. Stroop test. The Stroop test (Stroop, 1935) was designed as a measure of executive functioning. Typically participants are given two lists of colour words, and asked to read these aloud. The first list contains words printed in the congruent coloured ink, whereas the second list is printed in an incongruent colour. The accuracy and time taken for the participant to name the printed colour is then recorded. An interference measure is then calculated as the number of correctly named colours for the incongruent list, minus the correctly named colours for the congruent list. Therefore higher interference scores indicate superior interference/inhibitory control. The original Stroop task has been adapted into an 'Emotional Stroop' in which affective or personally relevant distractors are used instead of the incongruent colour words. Five studies used a version of the Stroop task to measure interference. Kemps and Wilsdon, (2010), Van den Eynde et al. (2012b), and Fagundo et al. (2012) used the original pencil and paper version of the Stroop task to examine differences between individuals with $\mathrm{BN}$ and HC. One study showed evidence for impaired interference control for BN compared to HC (Kemps \& Wilsdon, 2010), but the other study showed no differences between BN and HC (Van den Eynde et al., 2012b). Fagundo et al. (2012) found that individuals with AN were significantly impaired when compared to HCs. The final two studies used a computerised version of the Stroop (Ruiz et al., 2008) (Camacho Ruiz et al., 2008; Lee et al., 2017) that included food and body words. Camacho Ruiz et al. (2008) found that individuals with AN or BN showed a specific interference effect for negative body shape words, making more errors. In addition, individuals with BN took significantly longer for the negative word list compared to HCs. Similarly, Lee et al. (2017) observed significant differences between individuals with $\mathrm{BN}$ and healthy controls, with the BN sample showing lower accuracy. There were no statistically significant differences between $\mathrm{BN}$ and HC groups on response times; however, the BN sample showed the highest response times.

The Colour-Word Interference test is very similar to the Stroop task and also assesses interference control. Only one study (Brand et al., 2007) in the current review used this task, and found no evidence for adifference in performance between individuals with BN and HCs.

3.1.4.2. Hayling sentence completion test. The Hayling Sentence Completion Test (HSCT) was developed by Burgess and Shallice (1996), and measures the interference between response initiation and suppression. Participants are read two different sets of incomplete sentences, and are asked to respond by providing the last 
word to complete the sentence. In the first condition (HSCT- initiation), the response given by the participant has to fit the context of the sentence. However, in the second condition (HSCT-suppression), the response has to be irrelevant, although still grammatically correct (Borella et al., 2010). The outcome measure of interference cost is the total number of correct HSCT-suppression completions minus the correct HSCT-initiation completions. A lower score therefore indicates a deficit in interference/inhibitory control. Kemps and Wilsdon (2010) Abbate-Daga et al. (2011) and Aloi et al. (2015) used the standard version of the HSCT and showed mixed findings. Kemps and Wilsdon (2010) found that those with BN performed significantly worse than HCs. In a separate study, individuals with AN-R were also found to have a lower score compared to HCs (Abbate-Daga et al., 2011). However, Aloi et al. (2015) found no differences in performance between individuals with AN and HCs. The fourth study to use the HSCT (Pignatti and Bernasconi, 2013) adapted the original version to be used in Italian, with a reduced number of sentences in each condition. This study showed no evidence of a deficit in interference control for those with AN or BN compared to HCs.

3.1.4.3. Simon spatial incompatibility task (SSI). The SSI task measures the interference that results from the side of the screen that the stimulus appears on, and the direction that the stimulus points. During this task, stimuli are presented on the screen in the form of arrows, pointing to the left or right, and appearing on either the left or right of a central midline. Therefore, a congruent trial would be when an arrow pointed to the right and the stimulus appeared on the right, whereas an incongruent trial would be when an arrow pointed to the right but the stimulus appeared on the left. The main outcome measures are the time taken for the participant to respond, and the accuracy of response (number of errors). An interference measure is then calculated as the mean RTs for incongruent minus congruent trials, and accuracy for incongruent minus congruent trials. The one study to use this measure (Marsh et al., 2009) demonstrated that individuals with BN have smaller RT interference scores than HC, but make more interference errors. This indicates a speed accuracy trade off, whereby individuals with $\mathrm{BN}$ tend to respond as quickly as possible at the expense of accuracy.

3.1.4.4. Cued reaction time (RT) task. The cued RT task, similar to the SSI, measures proactive interference in two ways. Firstly, "preparation costs" reflects the extent to which participants' responses are slowed down when not all stimuli are targets for response. Secondly, "warning benefit" is the degree to which RT on cued trials benefit from longer stimulus onset asynchrony (e.g. 0 (no cue), 100, 300, or $500 \mathrm{~ms}$ till target appears). During the task, a fixation cross, flanked by two empty crosses, is continuously presented on the screen. On each trial, a visual target in the form of a large yellow dot appears in one of the two boxes. Participants are instructed to indicate the location of the target by pressing the corresponding arrow key as quickly as possible. On some trials, the target is preceded by a spatially uninformative warning cue. This cue is intended to reduce uncertainty regarding the requirement of a response, but gives no information regarding what motor response will be required: participants are informed that the presence of the cue is warning them that the target will soon be appearing, and are reminded to only respond to the target and not the cue. One study utilised this measure (Bartholdy et al., 2017) finding no differences between AN, BN, and HC groups on "preparation costs" (assessed by comparing mean RT's in all trials) nor "warning benefit".

\subsubsection{Risk taking}

Almost all real-world behaviour has a certain chance, or risk, of a given outcome, which could be positive or negative (Leigh, 1999; Lejuez et al., 2002). However, for the purpose of the current review, risk taking is defined as the engagement in behaviour to obtain a specific outcome that has an associated probability of being disadvantageous or potentially harmful (Leigh, 1999). The assessment of a construct such as risk taking is difficult, and has previously been measured using self-report instruments (Barratt, 1985; Eysenck et al., 1985; Whiteside et al., 2005). However, the degree to which subjective bias and social desirability can influence responses is debated (Ladouceur et al., 2000). Therefore, a more accurate assessment of risk taking should utilise a behavioural measure to reduce potential bias (Lejuez et al., 2002). Measures of risk taking employed in this review include the Bets-16 Task, Game of Dice Task and the Iowa Gambling Task.

3.1.5.1. Bets-16 task (Butler and Montgomery, 2005). During this task participants are given 16 pairs of two outcome hypothetical bets, presented in a pie chart format. Each pair of bets has an identical expected value; however one choice (guaranteed win) has a large likelihood of a win of a small amount of money vs. a small likelihood of winning a larger amount. In contrast the other choice (long shot) provides a small chance of winning a large amount, or a high chance of winning nothing. Points are awarded for each long shot chosen, which is the more 'risky choice'. The main outcome variable is this net score, and therefore, a higher overall score indicates more risk taking behaviour. There was only one study to use the Bets-16 Task in individuals with an eating disorder (AN). This study found no evidence of a difference between AN and HC in the number of risky decisions made (Butler and Montgomery, 2005).

3.1.5.2. Game of dice task. The Game of Dice Task (GDT) was designed by Brand et al. (2005) to assess risky decision making in a gambling situation. Participants are given an imaginary starting capital of $\$ 1,307$ and told to increase this amount through 18 rolls of the dice. At the beginning of each trial, participants are asked to choose a number that will occur in the next throw from a set of fixed options. These options have fixed probabilities of wins and losses, and the associated risk, along with the wins and losses can be easily determined by the participant. In addition, the participants receive immediate feedback based on the choices that they make. Choices are then categorised as either high risk (disadvantageous) or low risk (advantageous). The main outcome variable is calculated by subtracting the disadvantageous from the advantageous choices. Therefore a lower overall score would indicate a higher proportion of disadvantageous choices, indicating risky decision-making. Two studies (Brand et al., 2007; Van den Eynde et al., 2012b) examined differences between BN and HC using the GDT. Van den Eynde et al. (2012b) showed differences between BN and HC in the number of disadvantageous choices. However, Brand et al. (2007) demonstrated that individuals with $\mathrm{BN}$ choose the disadvantageous choice significantly more frequently, when compared to HCs and accordingly had a lower net score.

3.1.5.3. Iowa gambling task. The Iowa Gambling Task (IGT) was originally developed to assess real life decision-making in patients with damage to the ventromedial prefrontal cortex. Individuals with damage to this area choose outcomes that yield high immediate gains, despite losses in the future (Bechara et al., al.,1994). The IGT is thought to mimic real life decision making as it combines factors such as uncertainty, reward, and punishment, and assesses the ability of the individual to discount immediate rewards in favour of future gains (Dunn et al., 2006). The computerised version of the IGT consists of four identical looking decks of cards (A, B, C, \& D). Participants are given a hypothetical loan of $£ 2,000$ and told to make 100 choices between each of the four decks. The participants are told that although each selection will result in winning some money, there will also be immediate losses following some choices, and the aim is to win as much money as possible. Unknown to the participants, the values of the decks have already been determined. Decks A and B are labelled the disadvantageous decks which give higher rewards, but also larger losses and are therefore more risky. In contrast, decks C and D are 
labelled the advantageous decks as they pay out small amounts but rarely give losses and are therefore safer. The 100 choices are then divided into 5 blocks of 20, and a net score for each block is calculated. The net score for each block consists of the total choices from the advantageous decks C and D, subtracted from the disadvantageous A and $\mathrm{B}$ decks. In addition, a global net score can be computed as the mean of the choices made across all 100 trials.

Eight studies included in the current review examined IGT performance in individuals with an eating disorder, compared to those without (Abbate-Daga et al., 2011; Adoue et al., 2015; Aloi et al., 2015; Brogan et al., 2010; Danner et al., 2012; Fagundo et al., 2012; Liao et al., 2009; Tchanturia et al., 2012b). Liao et al. (2009) showed a significant difference in the net score for all five blocks, and in global net score between both individuals with BN and HCs and individuals with AN compared to HCs, with both eating disorder groups showing diminished decision making. Similarly, Brogan et al. (2010) demonstrated lower global net scores in BN vs. HC, and AN vs. HC, but no difference between eating disorder groups. Block net scores were significantly different for blocks 3 and 4 for BN vs. HC and significantly different for blocks 3, 4, and 5 between AN and HC, with BN and AN groups performing worse. In line with this, Tchanturia et al. (2012b) reported that a mixed gender sample of individuals with AN performed significantly worse compared to HCs for all blocks except the first. Additionally, Abbate-Daga et al. (2011) showed that individuals with AN-R consistently performed worse when compared to HCs for total score and for the first and last fifty trials; a result also shown by Fagundo et al. (2012) who found that individuals with AN compared to HCs performed worse across all five blocks and for total IGT score. However, Danner et al. (2012) only showed significantly lower performance for AN compared to HC groups for total scores, but not for any individual block scores. Further to this, Aloi et al. (2015) and Adoue et al. (2015) showed impaired performance for total IGT scores when comparing individuals with AN to HCs, but different pattern of results across scores for the individual blocks. Only scores for blocks three, four, and five were significantly different for AN vs. HC groups for Adoue et al. (2015), compared to blocks two and three for Aloi et al. (2015).

3.1.5.4. Balloon analogue risk task (BART). This computerised task models real-world risky decision making by requiring the participant to balance the potential for reward and loss. Participants are presented with a balloon on the computer screen, and told that they have the opportunity to win money by pressing a button and pumping the balloon up. Each pump of the balloon is incremental and the bigger the balloon is pumped the greater the potential reward, if the participant 'cashes out' before it explodes. The point at which the balloon overinflates and explodes is variable and participants are not told these contingencies. If the balloon bursts without the participant 'cashing in', then the earnings for that trial are lost. Risky decision making is measured as the adjusted average number of pumps on an unexploded balloon (Lejuez et al., 2002).

One study which examined performance on the BART in those with an ED showed that individuals with AN make significantly fewer risky decisions compared to HCs (Adoue et al., 2015). Individuals with AN made fewer balloon pumps on unexploded balloons compared to HCs, indicative of lower risky decision making.

\subsubsection{Planning}

Adequate planning is the ability to successfully organize a sequence of actions or behaviours in order to take the individual from a current state to a specified goal state (Unterrainer and Owen, 2006). Planning is involved in most everyday activities, and a lack of adequate planning has been suggested to be a part of impulsivity (Moeller et al., 2001). Tasks that have been used to measure planning ability include The Tower of London/Hanoi and The Rey-Osterrieth/Complex Figures Task.
3.1.6.1. The Tower of London. The Tower of London Task (TOL) requires participants to transfer different coloured beads between three rods, of varying length, so that larger beads are never put on top of smaller beads, in order to achieve a specified goal arrangement (Shallice, 1982). The difficulty of the task can be manipulated by changing the goal arrangement of the beads, or the initial bead placement. The task is hypothesised to involve elements of impulsivity, planning and visuo-spatial working memory. Two studies in the current review used the TOL to assess differences between HCs and ED groups. Brand et al. (2007) compared individuals with BN to HCs but found no differences in performance for the TOL task. Ruiz et al. (2008) compared those with BN, AN, and HC. Although there were no differences in the total number of movements, both AN and $\mathrm{BN}$ groups took significantly longer to complete the task compared to HCs.

3.1.6.2. Rey-Osterrieth complex figures task. Originally designed by Rey (1941) and standardised by Osterrieth (1944), the Rey-Osterrieth Complex Figures Task (ROCF) is hypothesised to assess visuospatial ability, nonverbal memory, planning and strategic organisation (Shin et al., 2006). During this task participants are asked to copy a complex geometric shape and then reproduce this shape immediately from memory and after a delay. These conditions provide information about memory, planning, and attention. To successfully copy the figure, the participant needs to attend to the figure and integrate visuospatial information about the elements, motor skills to copy, and successful planning of copying order. The delayed and immediate recall conditions additionally rely on non-verbal memory of visuo-spatial arrangements. The outcome measures of accuracy, order completed, and time to complete is used as a marker of an individual's ability. Higher accuracy is taken as an indication of better performance in visuospatial, nonverbal memory, and planning domains. Six studies examined ROCF performance in both ED groups and HCs. Studies varied on the outcome measures reported, and scoring methods. Lopez et al. (2008a), Roberts et al. (2011) and Sherman et al. (2006) reported order index, which is hypothesised to relate to the planning component on the task.

Roberts et al. (2011) examined differences between AN-R, AN-B, $\mathrm{BN}$, and HCs. All ED groups showed significantly lower order index scores when compared to HCs. However, only BN differed from HCs for accuracy and recall scores, performing significantly worse. Similarly, Sherman et al. (2006) found that AN patients had significantly lower order index scores, compared to HCs. Those with AN also performed worse for immediate and delayed recall accuracy, and copy to immediate recall. Lopez et al. (2008a) found no differences between AN, $\mathrm{BN}$, and HC groups for organisational strategy, but individuals with BN had significantly lower copy index and recall accuracy.

Brand et al. (2007) only reported delayed recall for the ROCF, showing significantly lower scores for individuals with BN compared to HCs. However, Danner et al. (2012) showed no differences between AN and HC groups for copy or recall accuracy. Ruiz et al. (2008) compared $\mathrm{AN}, \mathrm{BN}$, and HC groups for total number of recalled elements. Individuals with AN performed significantly worse when compared to BN and HC groups, and scores for the BN group were also significantly lower when compared to HCs.

3.1.6.3. Delay discounting/temporal discounting. Delay discounting or temporal discounting (TD) tasks typically involve participants indicating their preference between a smaller immediate award and a larger delayed award, wherein greater delay discounting/TD signifies a preference for the smaller, more immediate reward. An example of a TD task is the hypothetical monetary TD task developed by Rubia et al. (2009) which entails participants indicating their preference between a variable smaller immediate award ( $£ 0-£ 100$ ) and a larger delayed reward (fixed at $£ 100$ ) over 100 binary choices (25 choices at each of four delays: 1 week, 1 month, 1 year and 2 years). 
Three studies examined TD in eating disorder groups and healthy controls. Firstly, Bartholdy et al. (2017), who compared AN, BN, and HC groups, observed poorer task-based inhibitory control (i.e. a preference for smaller, sooner rewards) in the BN group compared with the AN group. Similarly, Kekic et al. (2016), who investigated differences between $\mathrm{BN}$ and $\mathrm{HC}$ groups, found that individuals with $\mathrm{BN}$ showed greater delay discounting/TD. Lastly, a third study (Steward et al., 2017) observed that AN-BP patients presented significantly higher levels of delay discounting than their restrictive counterparts. As such, there is some evidence to indicate that eating disordered individuals who engage in purging behaviours show greater propensity towards immediate gratification and a lower ability to delay rewards.

\subsection{Compulsivity}

Compulsive responding during a behavioural task can be defined as the production of persistent actions that have no obvious relationship to the overall task goal, often measured using total perseverative errors, following a shift of contingencies. However, the cognitive mechanisms underpinning these perseverative errors can vary. Some measures of compulsive, or perseverative, responding, ask participants to shift attention from one aspect of a stimulus (i.e. shape), towards another aspect (i.e. colour). Compulsive responding after this shift could be related to an inability to shift attention. However, when a task requires participants to shift from performing a response based on one rule (matching based on shape) to a different rule (matching based on colour), the participant needs to override a previously learnt rule, or stimulus-reinforcement association, to prevent perseverative errors. Although an inability with the first type of shift, attentional set-shifting, and the second type of shift, reversal learning, result in the same outcome, compulsive responding, the processes underlying the two behaviours is different. It has therefore been argued that these two processes should be distinguished when investigating cognitive inflexibility in EDs (Wildes et al., 2014). As such, studies examining attentional setshifting will be presented first, followed by those examining reversal learning. Tasks that measure both attentional set-shifting and reversal learning will be presented last.

\subsubsection{Attentional set-shifting}

3.2.1.1. Trail making task (Kravariti et al., 2003; Touolopoulo et al., 2003). The Trail Making Task (TMT) consists of two parts, Part A and B. During Part A, participants are asked to draw lines between 25 numbered circles in ascending order. Part B also involves connecting circles but during this part the circles include both numbers (1-13) and numbers (A-L) and participants are required to alternate between the numbers and letters (1-A-2-B, etc.). The outcome measures from this task are the time taken to complete Part A and Part B. A composite score can be calculated by subtracting Part A from Part B i.e. B-A. The task can be done using a pencil and paper or via computer program. Five papers in the current review used the TMT (Abbate-Daga et al., 2011; Aloi et al., 2015; Brand et al., 2007.; Holliday et al., 2005; Roberts et al., 2010b). Three studies found no differences on the time taken for individuals with AN to complete the TMT when compared to HCs (Abbate-Daga et al., 2011; Holliday et al., 2005; Roberts et al., 2010b). Further to this, Aloi et al. (2015) found no differences for time to complete parts A and B, or the composite B-A score for those with AN compared to HCs. However, the number of errors made during part $B$ was higher for those with AN. Similarly, Brand et al. (2007) found that there were no differences between individuals with BN and HCs on time taken to complete, but that those with BN made significantly more errors for part B.

\subsubsection{Perceptual set-shifting}

3.2.2.1. Haptic illusion task (Tchanturia et al., 2001; Uznadze, 1996). This task involves three wooden balls, two smaller balls of $5 \mathrm{~cm}$ in diameter, and one larger ball measuring $8 \mathrm{~cm}$ in diameter. The task is designed to measure perceptual shifting ability. Participants are asked to close their eyes and are asked to judge the size of the balls that are placed in each hand. To start, one small and large ball are placed in each hand a total of fifteen times. Then for the next fifteen trials both the small balls are given, and asked whether there is any difference in the size of the balls. Commonly, participants report that the hand previously holding the larger ball now contains a smaller ball. This is classified as an illusion, and the number of times this is experienced by the participant is used as a marker of perceptual rigidity. Two studies in the current review used the Haptic Illusion Task and showed a significantly higher number of illusions for individuals with AN compared to HCs (Holliday et al., 2014) and for ANR, ANBP, and BN groups compared to HCs (Roberts et al., 2010b).

\subsubsection{Reversal learning}

3.2.3.1. Probabilistic reversal learning task (Dombrovski et al., 2010). The Probabilistic Reversal Learning Task (PRLT) measures reversal learning during decision making, unaffected by working memory or problem solving ability. During the task, participants learn to choose one of two rectangles (red or green) over 80 trials. During the initial 40 trials (acquisition stage), the participant is rewarded for choosing the green rectangle on $80 \%$ of the trials, and punished for choosing the red triangle. On $20 \%$ of the trials, false feedback is provided so that selection of the green rectangle results in punishment and selection of the red rectangle results in reward. In the second 40 trial reversal stage, these probabilities are reversed. Participants who correctly respond to eight consecutive trials are considered to pass a stage. Perseverative errors capture the tendency to stay, while ignoring punishment feedback, whereas the tendency to switch too often leads to probabilistic switch errors. Adoue et al. (2015) found that the AN group had lower acquisition scores, higher total errors, and excessive switching compared to HCs. There were no differences in scores for the reversal stage or perseverative errors. However, after controlling for age and NART scores, none of these differences remained significant.

3.2.3.2. The Brixton spatial anticipation test (Burgess and Shallice, 1996). This task is designed to measure a participant's ability to detect a rule, follow this rule, and shift behaviour in line with a new rule. Participants are shown ten circles displayed in two horizontal rows of five circles, numbered from one to five. One of these circles is coloured blue on each trial. The placement of the blue circle varies on each trial and is determined by a pre-set rule, not told to the participant. Participants are asked to indicate the placement of the blue circle on the next trial based on the rule inferred from the previous trial. Responses are coded as correct if they follow the present rule, or if the rule changed and the response followed the new rule. The outcome measure of total errors (out of a possible 55) is used to indicate performance, with higher scores reflecting worse performance. Four studies used the Brixton Spatial Anticipation Test. Two compared performance in those with AN versus HCs (Adoue et al., 2015; Holliday et al., 2014) and two also included individuals with BN (Roberts et al., 2010b; Tchanturia et al., 2011). Results comparing individuals with AN to HCs were mixed. Although Adoue et al. (2015) showed that AN made more errors than HCs, Holliday et al. (2005) found no differences between groups. Studies that also included those with BN generally found that both ANR, ANBP and BN made more errors than HCs (Roberts et al., 2010b). However, although Tchanturia et al. (2011) found more errors in AN when compared to $\mathrm{BN}$ and HCs, there were no differences between BN and HCs.

3.2.3.3. The Cat Bat Task (Eliava, 1964; Tchanturia, Morris, Surguladze, and Treasure, 2002). The Cat Bat Task has been used as a measure of set shifting. Participants are presented with a short story and are asked to fill in the missing letters as accurately, but as quickly as possible. The first part of the story describes contexts in which the participant is 
prompted to use the letter ' $c$ ' to complete the fragment ' $a t$ ' to become 'cat'. The second part of the task, known as the shifting part, also requires inserting letters. However ' $c$ ' is no longer appropriate to the context of the story and ' $b$ ' becomes a more logical insertion to make 'bat'. Participants are therefore required to shift from a previously primed response (' $c$ '), to adapt to the contextual changes and respond with an alternate response (' $b$ '). Perseverative errors and time taken to complete the task are used as outcome measures. Only one study used the Cat Bat Task and showed that individuals with AN took longer for Bat time (after shift), when compared to HCs, but found no difference for perseverative errors (Holliday et al., 2005).

3.2.4. Tasks measuring attentional set-shifting and reversal learning

3.2.4.1. Wisconsin card sorting test (Grant and Berg, 1948). The Wisconsin Card Sorting Test (WCST) was designed to measure the ability to shift cognitive strategy in response to changing contingencies. The task has been hypothesised to measure a number of executive functions including attentional set shifting, task/rule switching or reversal, and working memory. Participants are presented with four cards that depict different colours and shapes. The number of shapes, and the formation of the shapes also differ. The participant is asked to match a card (presented under the four other cards) but not how to match. However, feedback is given and the participant is told whether the match is correct or not. During the task to matching/sorting rules are randomly varied and the participant must identify the new rule in order to correctly match the cards. Outcome measures from the task include the score/percentage of categories achieved, trials, errors, and perseverative errors. A total of thirteen studies used a version of the WCST to look at differences in performance, seven of which compared individuals with AN and HCs (Abbate-Daga et al., 2011; AbbateDaga et al., 2014; Aloi et al., 2015; Danner et al., 2012; Fagundo et al., 2012; Nakazato et al., 2009; Talbot et al., 2015), two compared individuals with BN and HCs (Brand et al., 2007; Galderisi et al., 2011) with the remaining four studies including both AN and BN groups compared to HCs (Camacho Ruiz, Escoto Ponce de León, and Mancilla Díaz, 2008; Pignatti and Bernasconi, 2013b; Roberts et al., 2010b; Tchanturia et al., 2012a). In all seven studies comparing AN and HCs, more perseverative errors were found in the AN group (Abbate-Daga et al., 2011, 2014; Aloi et al., 2015; Danner et al., 2012; Fagundo et al., 2012; Nakazato et al., 2009; Talbot et al., 2015). However, once correcting for BMI, differences in the Abbate-Daga et al. (2011) study were no longer significant.

The two studies that only included a BN and HC group did not find any differences between groups (Brand et al., 2007; Galderisi et al., 2011). However, the four studies that included a BN group alongside the AN group showed mixed findings. Camacho Ruiz et al. (2008) and Tchanturia et al., (2012a) found that both AN and BN groups made significantly more perseverative errors compared to HCs. Similarly, Roberts et al. (2010b) found that ANR, ANBP, and BN had more perseverative errors compared to HC. Pignatti and Bernasconi (2013) found no differences between the BN, AN and HC groups for perseverative errors.

3.2.4.2. CANTAB ID/ED set-shifting test (Downes et al., 1989). The Intra/Extra Dimensional (IDED) Task involves attentional set-shifting, visual discrimination and attentional set formation maintenance. The IDED is similar to the WCST with the exception that it is able to dissociate different aspects of cognitive flexibility. During the intradimensional shift stage, participants' ability to generate rules when novel stimuli are introduced is measured, whereas the extradimensional stage assesses the ability to shift attention away from previously relevant stimuli. The stimuli are made up of two dimensions; (1) coloured filled shapes and (2) white lines that appear in four rectangles on a computer screen. Simple stimuli are made up of just one of these dimensions, whereas compound stimuli are made up of both dimensions. The participant first starts by viewing two simple stimuli and learns, via feedback, which is the correct one by touching it. After six correct responses, the stimuli and/or rules are changed. These shifts are initially intra-dimensional (colour shapes remain the only relevant dimension), and then extra-dimensional (white lines are the only relevant dimension). Outcome measures include errors, number of trials, and stages completed. The one study to examine set-shifting in EDs using this task found no differences between ANR, ANBP, BN and HCs for any of the outcome measures (Galimberti et al., 2012).

\section{Discussion}

The aim of this review was to identify and summarise cross-sectional research comparing cognitive performance on measures of impulsivity and/or compulsivity between individuals with AN, or BN to HCs. Overall, the results of the review are highly variable, showing mixed results. The reasons for this are explored below.

\subsection{Impulsivity}

Studies examining impulsivity across individuals with AN or BN compared to HCs demonstrated mixed findings. There were no studies that examined action inhibition in those with AN. However, evidence for decreased action inhibition in BN, compared to HCs, was observed in a study that used disorder specific stimuli (food words). Three studies examining action cancellation included individuals with AN; one found evidence for and two found evidence against a deficit.

Similarly, the evidence for impairments in interference control was mixed. Studies in this category used different methods of assessment that could have contributed to the mixed findings. Four studies found no differences between individuals with BN and HCs across the different tasks used. However, three studies did find that individuals with BN had greater interference compared to HCs. Three studies looked at AN versus HC groups and showed impairments in interference control in the AN group. Method of assessment (pen and paper vs. computer) varied across studies, as did stimuli used (disorder relevant vs. neutral).

Findings for risky decision-making were also mixed when comparisons were made across different tasks. Although two paradigms (Bets16 \& BART) showed no evidence for increased risky decision-making in those with AN, compared to HCs, the findings were opposite for the IGT. Of the eight studies that compared individuals with AN to HCs on the IGT, all showed some impairment for the AN group. Two studies examining risky decision-making on the IGT in BN found impairments when compared to HCs.

The construct of planning was assessed in both AN and BN groups. Two paradigms were used to measure this construct; the TOL and the ROCFT. Two studies looked at differences between BN, AN, and HCs groups using the TOL, but found no clear differences in planning between groups. However, studies using the ROCFT found a more consistent pattern. Four studies that included individuals with BN found lower planning. Three out of the five studies to include AN found lower performance compared to HCs. However, the outcome measures used differed across studies, and consequently limits firm comparisons.

\subsection{Compulsivity}

Evidence for increased compulsivity across $\mathrm{AN}$ and $\mathrm{BN}$ groups was reviewed in the domains of attentional set-shifting, perceptual setshifting, and reversal learning. The majority of studies examining attentional set-shifting were conducted in AN $(N=4)$. Although all four studies showed no differences in time to complete the task, one study showed more errors for individuals with AN compared to HCs. Similarly, the one study to examine BN showed no differences in completion times, but more errors, when compared to HCs. Evidence of an impairment in perceptual set-shifting was present for both AN and BN. 
Studies examining reversal learning were largely carried out in AN. The tasks used to examine this construct were heterogeneous. One study (PRL task) found no differences between AN and HCs. Yet, studies that used the Brixton task found more consistent results. Three of these four studies found more errors for AN compared to HC, whilst one study found no differences. The two studies examining BN compared to HCs found opposing results. One study found higher errors, whereas the other failed to find any differences. There was only one study that used the Cat Bat task, and no differences in perseverative errors between those with AN and HCs were found. However, individuals with AN did take significantly longer to complete the task.

A total of thirteen studies used varying versions of the WCST to examine perseverative responding. All seven studies that compared AN to HCs showed increased perseverative errors for the AN group. The two studies examining differences between BN and HCs found no evidence of increased perseverative responding. Of the studies that included both AN and BN, three studies found group differences, whilst one study found no difference.

\subsection{Impulsivity and compulsivity as trans-diagnostic across EDs?}

The review has shown mixed findings for the cognitive performance of individuals with AN or BN, when compared to HCs on measures assessing aspects of impulsivity/compulsivity. There does not appear to be a clear differentiation between $\mathrm{AN}$ and $\mathrm{BN}$ in regard to increased/ decreased impulsivity or compulsivity; which is consistent with a transdiagnostic view. There is some evidence to suggest increased impulsivity in AN (interference/risky decision making), although the extent to which performance on these tasks reflects 'pure' impulsivity is debated. Findings from the IGT indicated higher risky decision making in those with AN compared to HCs. However, task performance could be related to a number of factors including sensitivity to reward and punishment, known to be affected in individuals with AN (Jappe et al., 2011). Additionally, the WCST measures interference but the task involves other executive functions, such as set-shifting. The ability to shift set has previously been shown to be disrupted in AN, and this view is supported by evidence in the current review. The conceptualisation of AN as having trait impairments in set-shifting and compulsive responding seems to be supported. However, problems with the tasks assessing multiple constructs limits the conclusions that can be drawn regarding AN and impulsivity.

This review did not find consistent evidence in favour of increased impulsivity in BN, when compared to HCs, across different measurements. There appeared to be a mixed picture, with some studies showing increased impulsivity, and others no effect. Studies showing increased impulsivity tended to incorporate disorder relevant stimuli (food words). Generally, the evidence does not seem to support the simplistic view of AN as a disorder of compulsivity, and BN as having problems of impulse control. Together the results point to a more balanced view of co-occurring impulsive and compulsive behaviour. This provides support to the view of impulsivity and compulsivity occurring trans-diagnostically, and has important clinical considerations for treatment and future research.

The discrete neuro-cognitive profiles thought to underpin behaviour unique to either $\mathrm{AN}$ or $\mathrm{BN}$ has not been supported by the evidence reviewed here and this raises the question of whether a complete and consistent understanding of impulsivity and compulsivity from a neurocognitive perspective is clinically meaningful when understanding EDs and identifying treatment targets. One driver for understanding the cognitive profile of the different EDs is that this can then be targeted in treatment, such as cognitive inflexibility in AN, which is targeted in CRT. However, research has shown that there is only a moderate to low correlation between most neuro-cognitive measures and everyday behaviour in those with an ED (Stedal and Dahlgren, 2015). The research evidence reviewed suggests that impulsivity and compulsivity are not diametric and can be present in both $\mathrm{AN}$ and $\mathrm{BN}$ across different contexts in the expression and regulation of both behaviour and emotions. This is more in line with the descriptions of over-and -under control provided by Lynch and colleagues, and may be a more clinically useful description.

\subsection{Limitations}

Comparisons between AN, BN, and HCs on measures of impulsivity or compulsivity are limited due to the heterogeneous tasks used to measure the same constructs. Additionally, studies utilising the same task, such as the ROCFT, reported different outcome measures (order index vs. delayed recall). This prevents comparisons between studies, and precludes any firm conclusions from being drawn. Additionally, it prevents the use of meta-analytic approaches to further understand subcomponents of impulsivity or compulsivity. The use of heterogeneous tasks and outcomes could be framed as a relative strength had there been consistent results found. Any emerging consistent findings despite the variety of methods and timing of data collection could suggest a robust finding of a possible latent neurocognitive construct that underpinned performance across tasks. However, the results were not consistent and some of the measures included in the current review, such as the IGT and WCST, have been criticised for involving and assessing multiple processes. This makes the interpretation of results more complex, and impairments on these tasks could be related to one or more of these processes. Furthermore, the distribution of studies looking at impulsive traits tended to include $\mathrm{BN}$, whereas the examination of compulsive traits tended to examine AN.

A further limitation of the synthesis of the evidence in this way is the assumption that the studies included similar ED groups, and that tasks were administered in a similar manner across studies. Differences in task administration (pen and paper vs. computer) may have biased results, particularly for outcome measures involving reaction times. Stedal and Dahlgren (2015) investigated the relationship between performance based neuropsychological assessments and self-report measures in adolescents with AN. Results showed that with a few exceptions, the majority of tasks included in the battery (Ravello profile) showed little correlation to the self-report measure of 'everyday' behaviour, again highlighting a need to be cautious when interpreting the generalisability of results on neurocognitive tasks.

It is also likely that there may be differences in the included patient groups that could confound the results. Patients may have differed according to current medication, general intelligence, co-morbidities, and state of starvation. Although BN and HCs are often matched for BMI, this is not the case for AN. Individuals with AN, by definition, are at a significantly lower body weight; often accompanied by symptoms of starvation.. Studies rarely reported sufficient information about recruitment to determine the degree to which this could have affected findings. Similarly, although individuals with BN were generally matched to HCs for BMI, such individuals routinely fast and no measure of this was taken. McConnellogue (2012) found that $60 \%$ of individuals with BN reported (on the EDE-Q6) having fasted for a minimum of eight hours on at least 1 of the last 28 days. This indicates that short-term fasting is common in individuals with BN, and is not reflected by a low BMI. Research has also demonstrated that fasting, even in HCs, can impact on measures of impulsivity (Howard et al., 2020; Symmonds et al., 2010)

Another issue that limits comparisons between the different patient groups and healthy controls are comorbidities associated with the disorder. Outcome measures need to be considered in relation to comorbidities such as anxiety, depression and (in AN) low body weight. Anxiety and depression have both been shown to affect cognitive function (Austin et al., 2001).

A limitation of this review was the exclusion of studies that did not categorise individuals into groups based on diagnostic criteria. This means that studies categorising individuals according to symptoms, such as AN restrictive subtype or AN bingeing-purging subtype were not 
included (Claes et al., 2001). Although this approach was recommended, comparing results of studies according to symptoms to existing data based on diagnostic groups is difficult due to differences in the included patients. However, the exclusion of these studies could have biased the results of the review. Future research should reach a consensus and take a consistent approach to defining the different patient groups for inclusion into research studies.

\subsection{Future considerations}

This systematic evaluation of the existing literature highlights important areas of improvement and investigation for future research studies in neurocognition. Future studies should conduct power calculations to estimate the required sample size in order to be able to detect differences between groups, if present. Main outcome measures should be defined a priori, with reporting of effect sizes. Tasks that isolate the separate components of impulsivity and compulsivity should be prioritised but this could lead to problems comparing current evidence to previous literature. A consensus needs to be reached on the appropriate paradigms to measure different constructs so that the same outcome measures from different studies can be compared, preferentially in a meta-analysis. The current results also suggest that impulsivity and compulsivity are not separable components and cognitive tasks assessing these constructs should be mapped to clinical descriptions of behaviour. Whilst a more strategic approach to methodology and reporting would aid the development of more robust cognitive profiles, it may also be worth considering the benefit to our understanding of EDs and treatment as a whole. For example, conceptualising EDs as a mixture of behaviours of under-and-over control that can present in the same individual may be more helpful in formulating treatment approaches and in understanding the common temporal movement between symptoms. This would then indicate the need to formulate and treat both under-and-over control (Hempel et al., 2018). In conclusion, the results of the current review suggest no consistent neurocognitive profile characterising $\mathrm{AN}$ as a disorder of compulsivity and BN as a disorder of impulsivity. Instead, increased performance on cognitive measures of impulsivity and compulsivity are demonstrated, to some degree, across $\mathrm{AN}$ and $\mathrm{BN}$.

\section{Declaration of Competing Interest}

The authors whose names are listed immediately below certify that they have NO affiliations with or involvement in any organization or entity with any financial interest (such as honoraria; educational grants; participation in speakers' bureaus; membership, employment, consultancies, stock ownership, or other equity interest; and expert testimony or patent-licensing arrangements), or non-financial interest (such as personal or professional relationships, affiliations, knowledge or beliefs) in the subject matter or materials discussed in this manuscript.

\section{Supplementary materials}

Supplementary material associated with this article can be found, in the online version, at doi:10.1016/j.psychres.2020.113354.

\section{References}

Abbate-Daga, G., Buzzichelli, S., Amianto, F., Rocca, G., Marzola, E., McClintock, S.M., Fassino, S., 2011. Cognitive flexibility in verbal and nonverbal domains and decision making in anorexia nervosa patients: a pilot study. BMC Psychiatry 11, 162. https:// doi.org/10.1186/1471-244X-11-162.

Abbate-Daga, G., Buzzichelli, S., Marzola, E., Amianto, F., Fassino, S., 2014. Clinical investigation of set-shifting subtypes in anorexia nervosa. Psychiatry Res. 219 (3), 592-597. https://doi.org/10.1016/j.psychres.2014.06.024.

Adoue I., J., C., Oilie, E., Beziat, S., Van den Eynde, F., Courtet, P., Guillaume, S., 2015a. A further assessment of decision-making in anorexia nervosa. Eur. Psychiatry 30 (1),
121-127. https://doi.org/10.1016/j.psychres.2004.12.01.

Ágh, T., Kovács, G., Supina, D., 2016. A systematic review of the health-related quality of life and economic burdens of anorexia nervosa, bulimia nervosa, and binge eating disorder. Eat Weight Disord. 21, 353-364. https://doi.org/10.1007/s40519-0160264-X.

Agras, W., Walsh, B., Fairburn, C.G., Wilson, G.T., Kraemer, H.C., 2000. A multicenter comparison of cognitive-behavioral therapy and interpersonal psychotherapy for bulimia nervosa. Arch. Gen. Psychiatry 57 (5), 459-466. https://doi.org/10.1001/ archpsyc.57.5.459.

Aloi, M., Rania, M., Caroleo, M., Bruni, A., Palmieri, A., Cauteruccio, M.A., Segura-Garcia, C., 2015a. Decision making, central coherence and set-shifting: a comparison between Binge Eating Disorder, Anorexia Nervosa and Healthy Controls. BMC Psychiatry 15 (6). https://doi.org/10.1186/s12888-015-0395-z.

Anderluh, M., Tchanturia, K., Rabe-Hesketh, S., Treasure, J., 2003. Childhood obsessivecompulsive personality traits in adult women with eating disorders: defining a broader eating disorder phenotype. Am. J. Psychiatry 160 (2), 242-247.

Austin, M.P., Mitchell, P.B., Goodwin, G.M., 2001. Cognitive deficits in depression possible implications for functional neuropathology. Br. J. Psychiatry 178 (3), 200-206. https://doi.org/10.1192/bjp.178.3.200.

Barratt, E.S., 1985. Impulsiveness subtraits: arousal and information processing. In: Spence, J.T., Itard, C.E. (Eds.), Motivation, emotion, and Personality. Elsevier, Amsterdam, pp. 137-146.

Bartholdy, S., Rennalls, S., Danby, H., Jacques, C., Campbell, I.C., Schmidt, U., O’Daly, O.G., 2017. Temporal Discounting and the Tendency to Delay Gratification across the Eating Disorder Spectrum. Eur. Eat Disord. Rev. 25 (5), 344-350. https://doi.org/10. 1002/erv.2513.

Bechara, A., Damasio, A.R., Damasio, H., Anderson, S.W., 1994. Insensitivity to Future Consequences Following Damage to Human Prefrontal Cortex. Cognition 50 (1-3), 7-15. https://doi.org/10.1016/0010-0277(94)90018-3.

Boisseau, C.L., Thompson-Brenner, H., Caldwell-Harris, C., Pratt, E., Farchione, T., Harrison Barlow, D., 2012a. Behavioral and cognitive impulsivity in obsessive-compulsive disorder and eating disorders. Psychiatry Res. 200 (2-3), 1062-1066. https:// doi.org/10.1016/j.psychres.2012.06.010.

Boisseau, C.L., Thompson-Brenner, H., Eddy, K.T., Satir, D.A., 2009. Impulsivity and personality variables in adolescents with eating disorders. J. Nerv. Ment. Dis. 197 (4), 251-259. https://doi.org/10.1097/NMD.0b013e31819d96c0.

Borella, E., Carretti, B., Pelegrina, S., 2010. The specific role of inhibition in reading comprehension in good and poor comprehenders. J. Learn. Disabil. 43 (6), 541-552. https://doi.org/10.1177/0022219410371676.

Brand, M., Franke-Sievert, C., Jacoby, G.E., Markowitsch, H.J., Tuschen-Caffier, B., 2007. Neuropsychological correlates of decision making in patients with bulimia nervosa. Neuropsychology 21 (6), 742-750. https://doi.org/10.1037/0894-4105.21.6.742.

Brand, M., Fujiwara, E., Borsutzky, S., Kalbe, E., Kessler, J., Markowitsch, H.J., 2005. Decision-making deficits of korsakoff patients in a new gambling task with explicit rules: associations with executive functions. Neuropsychology 19 (3), 267-277. https://doi.org/10.1037/0894-4105.19.3.267.

Brecelj-Anderluh, M., Tchanturia, K., Rabe-Hesketh, S., Treasure, J., 2003. Childhood obsessive-compulsive personality traits in adult women with eating disorders: defining a broader eating disorder phenotype. Am. J. Psychiatry 160, 242-247.

Brogan, A., Hevey, D., Pignatti, R., 2010. Anorexia, bulimia, and obesity: shared decision making deficits on the Iowa Gambling Task (IGT). J. Int. Neuropsychol. Soc. 16 (4), 711-715. https://doi.org/10.1017/S1355617710000354.

Bruce, K.R., Koerner, N.M., Steiger, H., Young, S.N., 2003. Laxative misuse and behavioral disinhibition in bulimia nervosa. Int. J. Eat. Disord. 33 (1), 92-97. https://doi. org/10.1002/Eat.10116.

Burgess, P.W., Shallice, T., 1996. Response suppression, initiation and strategy use following frontal lobe lesions. Neuropsychologia 34 (4), 263-272. https://doi.org/10. 1016/0028-3932(95)00104-2.

Butler, G.K., Montgomery, A.M., 2005. Subjective self-control and behavioural impulsivity coexist in anorexia nervosa. Eat. Behav. 6 (3), 221-227. https://doi.org/10. 1016/j.eatbeh.2004.11.002.

Camacho Ruiz, E.J., Escoto Ponce de León, M.d.C., Mancilla Díaz, J.M., 2008. Neuropsychological evaluation in patients with eating disorders. Salud. Mental. 31 (6), 441-446.

Carral-Fernandez, L., Gonzalez-Blanch, C., Goddard, E., Gonzalez-Gomez, J., BenitoGonzalez, P., Bustamante-Cruz, E., Gomez Del Barrio, A., 2016. Planning Abilities in Patients with Anorexia Nervosa Compared with Healthy Controls. Clin. Neuropsychol. 30 (2), 228-242. https://doi.org/10.1080/13854046.2016.1147603.

Chen, E.Y., Segal, K., Weissman, J., Zeffiro, T.A., Gallop, R., Linehan, M.M., Bohus, M., Lynch, T.R., 2015. Adapting dialectical behavior therapy for outpatient adult anorexia nervosa-a pilot study. Int. J. Eat. Disord. 48 (1), 123-132. https://doi.org/10. $1002 /$ eat.22360.

Claes, L., Nederkoorn, C., Vandereycken, W., Guerrieri, R., Vertommen, H., 2006. Impulsiveness and lack of inhibitory control in eating disorders. Eat. Behav. 7 (3), 196-203. https://doi.org/10.1016/j.eatbeh.2006.05.001.

Claes, L., Vandereycken, W., Vertommen, H., 2001. Self-injurious behaviors in eatingdisordered patients. Eat. Behav. 2 (3), 262-272. https://doi.org/10.1016/S14710153(01)00033-2.

Claes, L., Vandereycken, W., Vertommen, H., 2005. Impulsivity-related traits in eating disorder patients. Pers. Individ. Dif. 39 (4), 739-749. https://doi.org/10.1016/j.paid. 2005.02.022.

Collantoni, E., Michelon, S., Tenconi, E., Degortes, D., Titton, F., Manara, R., Favaro, A., 2016. Functional connectivity correlates of response inhibition impairment in anorexia nervosa. Psychiatry Res. Neuroimaging 247, 9-16. https://doi.org/10.1016/j. pscychresns.2015.11.008.

Dahlgren, C.L., Lask, B., Landro, N.I., Ro, O., 2014. Developing and evaluating cognitive 
remediation therapy (CRT) for adolescents with anorexia nervosa: a feasibility study. Clin. Child Psychol. Psychiatry 193 (3), 476-487. https://doi.org/10.1177/ 1359104513489980.

Dalle Grave, R., Calugi, S., Marchesini, G., 2008. Compulsive exercise to control shape or weight in eating disorders: prevalence, associated features, and treatment outcome. Compr. Psychiatry 49 (4), 346-352. https://doi.org/10.1016/j.comppsych.2007.12. 007.

Dalley, J.W., Everitt, B.J., Robbins, T., 2011. Impulsivity, compulsivity, and top-down cognitive control. Neuron 69 (4), 680-694. https://doi.org/10.1016/j.neuron.2011. 01.020

Danner, U.N., Sanders, N., Smeets, P.A., van Meer, F., Adan, R.A., Hoek, H.W., van Elburg, A.A., 2012. Neuropsychological weaknesses in anorexia nervosa: set-shifting, central coherence, and decision making in currently ill and recovered women. Int. J. Eat. Disord. 45 (5), 685-694. https://doi.org/10.1002/eat.22007.

Daruna, J.H., Barnes, P.A., 1993. A neurodevelopmental view of impulsivity. In: McGown, W.G., Jongons, J.L., Shure, M.B. (Eds.), The Impulsive client: Theory, research, and Treatment. American Psychological Association, Washington, DC, US.

Dombrovski, A., Clark, L., Siegle, G., Butters, M., Ichiwaka, N., Sahakian, B., Szanto, K., 2010. Reward/punishment reversal learning in older suicide attempters. Am. J. Psychiatry 167 (7), 699-707. https://doi.org/10.1176/appi.ajp.2009.09030407.

Downes, J., Roberts, A., Sahakian, B., Evenden, J.L., Morris, R., Robbins, T., 1989. Impaired extra-dimensional shift performance in medicated and unmedicated Parkinson's disease: evidence for a specific attentional dysfunction. Neuropsychologia 27 (11), 1329-1343. https://doi.org/10.1016/0028-3932(89) 90128-0.

Dunn, B.D., Dalgleish, T., Lawrence, A.D., 2006. The somatic marker hypothesis: a critical evaluation. Neurosci. Biobehav. Rev. 30 (2), 239-271. https://doi.org/10.1016/j. neubiorev.2005.07.001

Duschesne, M., Mattos, P., Fontelle, L.F., Veiga, H., Rizo, L., Appolinario, J., 2004 Neuropsychology of eating disorders: a systematic review of the literature. Revista Brasileira de Psiquiatria 26 (2), 107-117.

Eagle, D.M., Bari, A., Robbins, T.W., 2008. The neuropsychopharmacology of action in hibition: cross-species translation of the stop-signal and go/no-go tasks. Psychopharmacology (Berl.) 199 (3), 439-456. https://doi.org/10.1007/s00213008-1127-6.

Eddy, K., Dorer, D.J., Franko, D.L., Tahilani, K., Thompson-Brenner, H., Herzog, D.B., 2008. Diagnostic crossover in anorexia nervosa and bulimia nervosa: implications for DSM-V. Am. J. Psychiatry 165 (2), 245-250.

Eliava, N., 1964. A Problem of Set in Cognitive Psychology. Academic Press, Tbilisi, Georgia.

Evenden, J.L., 1999. Varieties of impulsivity, Psychopharmocology 146 (4), 348-361.

Eysenck, S.B.G., Pearson, P.R., Easting, G., Allsopp, J.F., 1985. Age Norms for Impulsiveness, Venturesomeness and Empathy in Adults. Pers. Individ. Dif. 6 (5), 613-619. https://doi.org/10.1016/0191-8869(85)90011-X.

Fagundo, A.B., De la Torre, R., Jiménez-Murcia, S., Agüera, Z., Granero, R., Tárrega, S. Rodríguez, R., 2012. Executive functions profile in extreme eating/weight conditions: from anorexia nervosa to obesity. PLoS ONE 7 (8), e43382. https://doi.org/10.1371/ journal.pone.0043382.

Fairburn, C.G., Cooper, Z., Shafran, R., 2003. Cognitive behaviour therapy for eating disorders: a "transdiagnostic" theory and treatment. Behav. Res. Ther. 41 (5), 509-528. https://doi.org/10.1016/S0005-7967(02)00088-8.

Favaro, A., Zanetti, T., Tenconi, E., Degortes, D., Ronzan, A., Veronese, A., Santonastaso, P., 2005. The Relationship Between Temperament and Impulsive Behaviors in Eating Disordered Subjects. Eat. Disord. J. Treat. Prevent. 13 (1), 61-70. https://doi.org/10. 1080/10640260590893647.

Fernandez-Aranda, F., Nunez, A., Martinez, C., Krug, I., Capozzo, M., Carrard, I., Lam, T., 2009. Internet-based cognitive-behavioral therapy for bulimia nervosa: a controlled study. CyberPsychol. Behav. 12 (1), 37-41. https://doi.org/10.1089/cpb.2008.0123.

First, M.B., Pincus, H.A., Levine, J.B., Williams, J.B.W., Ustun, B., Peele, R., 2004. Clinical utility as a criterion for revising psychiatric diagnoses. Am. J. Psychiatry 161, 946-954.

Galderisi, S., Bucci, P., Mucci, A., Bellodi, L., Cassano, G., Santonastaso, P., Monteleone, P., 2011. Neurocognitive functioning in bulimia nervosa: the role of neuroendocrine, personality and clinical aspects. Psychol. Med. 41 (04), 839-848. https://doi.org/10. 1017/S0033291710001303.

Galimberti, E., Martoni, R.M., Cavallini, M.C., Erzegovesi, S., Bellodi, L., 2012a. Motor inhibition and cognitive flexibility in eating disorder subtypes. Prog. Neuropsychopharmacol. Biol. Psychiatry 36 (2), 307-312. https://doi.org/10.1016/ j.pnpbp.2011.10.017.

Godier, L.R., Park, R.J., 2014. Compulsivity in anorexia nervosa: a transdiagnostic concept. Front. Psychol. 5. https://doi.org/10.3389/fpsyg.2014.00778.

Gottesman, I.I., Gould, T.D., 2003. The endophenotype concept in psychiatry: etymology and strategic intentions. Am. J. Psychiatry 160 (4), 636-645.

Grant, D., Berg, E., 1948. A behavioral analysis of degree of reinforcement and ease of shifting to new responses in a Weigl-type card-sorting problem. J. Exp. Psychol. 38 (4), 404-411. https://doi.org/10.1037/h0059831.

Happe, F., Frith, U., 2006. The weak coherence account: detail-focused cognitive style in autism spectrum disorders. J. Autism Dev. Disord. 36 (1), 5-25. https://doi.org/10. $1007 /$ s10803-005-0039-0.

Hempel, R.J., Rushbrook, S.C., O'Mahen, H., Lynch, T.R., 2018. How to differentiate overcontrol from undercontrol: findings from the RefraMED study and guidelines from clinical practice. Behav. Therapist 41 (2), 132-141.

Hill, D.M., Craighead, L.W., Safer, D.L., 2011. Appetite-focused dialetical behavior therapy for the treatment of binge eating with purging: a preliminary trial. Int. J. Eat. Disord. 44 (249-261).

Holliday, J., Tchanturia, K., Landau, S., Collier, D., Treasure, J., 2005. Is impaired set- shifting an endophenotype of anorexia nervosa? Am. J. Psychiatry 162 (12), 2269-2275. https://doi.org/10.1176/appi.ajp.162.12.2269.

Holliday, J., Uher, R., Landau, S., Collier, D., Treasure, J., 2006. Personality pathology among individuals with a lifetime history of anorexia nervosa. J. Pers. Disord. 20 (4), 417-430. https://doi.org/10.1521/pedi.2006.20.4.417.

Howard, M., Poiser, J., Gilbert, S., Burgess, P., Dayan, P., Serpell, L., 2020. Short-Term Fasting Selectively Influences Impulsivity in Healthy Individuals. Front. Psychol. 11. https://doi.org/10.3389/fpsyg.2020.01644.

Jappe, L., Frank, G., Shott, M., Rollin, M., Pryor, T., Hagman, J., Yang, T., Davis, E., 2011. Heightened sensitivity to reward and punishment in anorexia nervosa. The International journal of eating disorders 317-324.

Juni, P., Altman, D.G., Egger, M., 2001. Assessing the quality of randomised controlled trials. Systematic Reviews in Health Care: Meta-Analysis in Context, 2nd edn. pp. 87-108.

Keel, P., Mitchell, J.E., 1997. Outcome in bulimia nervosa. Am. J. Psychiatry 154 (3), 313.

Kekic, M., Bartholdy, S., Cheng, J., McClelland, J., Boysen, E., Musiat, P., Schmidt, U., 2016. Increased temporal discounting in bulimia nervosa. Int. J. Eat. Disord. 49 (12), 1077-1081. https://doi.org/10.1002/eat.22571.

Kemps, E., Wilsdon, A., 2010a. Preliminary evidence for a role for impulsivity in cognitive disinhibition in bulimia nervosa. J. Clin. Exp. Neuropsychol. 32 (5), 515-521. https://doi.org/10.1080/13803390903264122.

Klump, K.L., Bulik, C.M., Kaye, W.H., Treasure, J., Tyson, E., 2009. Academy for Eating Disorders position paper: eating disorders are serious mental illnesses. Int. J. Eat. Disord. 42 (2), 97-103. https://doi.org/10.1002/eat.20589.

Kravariti, E., Morris, R.G., Rabe-Hesketh, S., Murray, R.M., Frangou, S., 2003. The Maudsley Early-Onset Schizophrenia Study: cognitive function in adolescent-onse schizophrenia. Schizophr. Res. 65 (2), 95-103. https://doi.org/10.1016/S09209964(03)00067-7.

Ladouceur, R., Bouchard, C., Rheaume, N., Jacques, C., Ferland, F., Leblond, J., Walker, M., 2000. Is the SOGS an accurate measure of pathological gambling among children, adolescents and adults? J. Gambl. Stud. 16 (1), 1-24. https://doi.org/10.1023/ A:1009443516329.

Lang, K., Roberts, M., Harrison, A., Lopez, C., Goddard, E., Khondoker, M., Tchanturia, K., 2014. Central coherence in eating disorders: an updated systematic review and metaanalysis. World J. Biol. Psychiatry 15 (8). https://doi.org/10.3109/15622975.2014. 909606.

Lee, J.E., Namkoong, K., Jung, Y.C., 2017. Impaired prefrontal cognitive control over interference by food. images in binge-eating disorder and bulimia nervosa. Neurosci. Lett. 651, 95-101. https://doi.org/10.1016/j.neulet.2017.04.054.

Leigh, B.C., 1999. Peril, chance, adventure: concepts of risk, alcohol use and risky behavior in young adults. Addiction 94 (3), 371-383. https://doi.org/10.1046/j.13600443.1999.9433717.x.

Lejuez, C.W., Read, J.P., Kahler, C.W., Richards, J.B., Ramsey, S.E., Stuart, G.L., Brown, R.A., 2002a. Evaluation of a behavioral measure of risk taking: the Balloon Analogue Risk Task (BART). J. Exp. Psychol. Appl. 8 (2), 75-84. https://doi.org/10.1037/ 1076-898X.8.2.75.

Liao, P.C., Uher, R., Lawrence, N., Treasure, J., Schmidt, U., Campbell, I.C., Tchanturia, K., 2009a. An examination of decision making in bulimia nervosa. J. Clin. Exp. Neuropsychol. 31 (4), 455-461. https://doi.org/10.1080/13803390802251378.

Liberati, A., Altman, D.G., Tetzlaff, J., Mulrow, C., Gotzsche, P.C., Ioannidis, J.P., Moher, D., 2009. The PRISMA statement for reporting systematic reviews and meta-analyses of studies that evaluate health care interventions: explanation and elaboration. Ann. Intern. Med. 151 (4), W-65. https://doi.org/10.1016/j.jclinepi.2009.06.006.

Logan, G.D., 1994. On the ability to inhibit thought and action: a users' guide to the stop signal paradigm. In: Dagenbach, D., Carr, T.H. (Eds.), Inhibitory Processes in attention, memory, and Language. Academic Press, pp. 189-239.

Lopez, C., Tchanturia, K., Stahl, D., Booth, R., Holliday, J., Treasure, J., 2008a. An examination of the concept of central coherence in women with anorexia nervosa. Int. J. Eat. Disord. 41 (2), 143-152. https://doi.org/10.1002/eat.20478.

Lopez, C.A., Tchanturia, K., Stahl, D., Treasure, J., 2008b. Central coherence in women with bulimia nervosa. Int. J. Eat. Disord. 41 (4), 340-347. https://doi.org/10.1002/ eat.20511.

Lynch, T.R., Gray, K.L., Hempel, R.J., 2013. Radically open-dialectical behavior therapy for adult anorexia nervosa: feasibility and outcomes from an inpatient program. BMC Psychiatry 13, 293. https://doi.org/10.1186/1471-244X-13-293.

Marsh, R., Steinglass, J.E., Gerber, A.J., Graziano O'Leary, K., Wang, Z., Murphy, D., Peterson, B.S., 2009. Deficient activity in the neural systems that mediate self-regulatory control in bulimia nervosa. Arch. Gen. Psychiatry 66 (1), 51-63. https://doi. org/10.1001/archgenpsychiatry.2008.504.

McCluskey, S., Evans, C., Lacey, J.H., Pearce, J.M., Jacobs, H., 1991. Polycystic ovary syndrome and bulimia. Fertil. Steril. 55 (2), 287-291. https://doi.org/10.1016/0020 7292(92)91015-G.

McConnellogue, D., 2012. Set shifting, Central Coherence and Starvation in Eating disorders. (D.Clin.Psy.). University College London, London.

Mobbs, O., Van der Linden, M., d'Acremont, M., Perroud, A., 2008. Cognitive deficits and biases for food and body in bulimia: investigation using an affective shifting task. Eat Behav. 9 (4), 455-461. https://doi.org/10.1016/j.eatbeh.2008.07.002.

Moeller, F.G., Barratt, E.S., Dougherty, D.M., Schmitz, J.M., Swann, A.C., 2001. Psychiatric aspects of impulsivity. Am. J. Psychiatry 158 (11), 1783-1793. https:// doi.org/10.1176/appi.ajp.158.11.1783.

Murphy, F.C., Sahakian, B.J., Rubinsztein, J.S., Michael, A., Rogers, R.D., Robbins, T.W., Paykel, E.S., 1999. Emotional bias and inhibitory control processes in mania and depression. Psychol. Med. 29 (6), 1307-1321. https://doi.org/10.1017/ S0033291799001233.

Nakazato, M., Tchanturia, K., Schmidt, U., Campbell, I., Treasure, J., Collier, D., Iyo, M., 2009. Brain-derived neurotrophic factor (BDNF) and set-shifting in currently ill and 
recovered anorexia nervosa (AN) patients. Psychol. Med. 39 (06), 1029-1035. https://doi.org/10.1017/S0033291708004108.

Newton, J., Freeman, C.P., Munro, J., 1993. Impulsivity and dyscontrol in bulimia nervosa: is impulsivity an independent phenomenon or a marker of severity? Acta Psychiatrica Scandinavica 87 (6). https://doi.org/10.1111/j.1600-0447.1993. tb03393.x.

Nigg, J.T., 2000. On inhibition/disinhibition in developmental psychopathology: views from cognitive and personality psychology and a working inhibition taxonomy. Psychol. Bull. 126 (2), 220-246. https://doi.org/10.1037//0033-2909.126.2.220.

Olmos, M., Antelo, M., Vazquez, H., Smecuol, E., Maurino, E., Bai, J.C., 2008. Systematic review and meta-analysis of observational studies on the prevalence of fractures in coeliac disease. Digestive and Liver Disease 40 (1), 46-53. https://doi.org/10.1016/j. dld.2007.09.006.

Osterrieth, P.A., 1944. The test of copying a complex figure: a contribution to the study of perception and memory. Arch. Psychol. 30, 206-356.

Pignatti, R., Bernasconi, V., 2013. Personality, clinical features, and test instructions can affect executive functions in Eating Disorders. Eat. Behav. 14 (2), 233-236. https:// doi.org/10.1016/j.eatbeh.2012.12.003.

Rey, A. (1941). L'examen psychologique dans les cas d'encéphalopathie traumatique.(Les problems). Archives de psychologie.

Robbins, T.W., Gillan, C.M., Smith, D.G., de Wit, S., Ersche, K.D., 2012. Neurocognitive endophenotypes of impulsivity and compulsivity: towards dimensional psychiatry. Trends Cogn. Sci. 16 (1), 81-91. https://doi.org/10.1016/j.tics.2011.11.009.

Roberts, M., Lavender, A., Tchanturia, K., 2011a. Measuring self-report obsessionality in anorexia nervosa: maudsley Obsessive-Compulsive Inventory (MOCI) or obsessivecompulsive inventory-revised (OCI-R)? Eur. Eat. Disord. Rev. 19 (6), 501-508. https://doi.org/10.1002/erv.1072.

Roberts, M.E., Barthel, F.M., Lopez, C., Tchanturia, K., Treasure, J.L., 2011 b. Development and validation of the Detail and Flexibility Questionnaire (DFlex) in eating disorders. Eat. Behav. 12 (3), 168-174. https://doi.org/10.1016/j.eatbeh. 2011.04.001.

Roberts, M.E., Tchanturia, K., Stahl, D., Southgate, L., Treasure, J., 2007. A systematic review and meta-analysis of set-shifting ability in eating disorders. Psychol. Med. 37 (08), 1075-1084. https://doi.org/10.1017/S0033291707009877.

Roberts, M.E., Tchanturia, K., Treasure, J., 2010. Exploring the neurocognitive signature of poor set-shifting in anorexia and bulimia nervosa. J. Psychiatr. Res. 44 (14), 964-970. https://doi.org/10.1016/j.jpsychires.2010.03.001.

Roberts, M.E., Tchanturia, K., Treasure, J.L., 2003. Is attention to detail a similarly strong candidate endophenotype for anorexia nervosa and bulimia nervosa? World J. Biol. Psychiatry 14 (6), 452-463. https://doi.org/10.3109/15622975.2011.639804.

Rosval, L., Steiger, H., Bruce, K., Israel, M., Richardson, J., Aubut, M., 2006. Impulsivity in women with eating disorders: problem of response inhibition, planning, or attention? Int. J. Eat. Disord. 39 (7), 590-593. https://doi.org/10.1002/eat.20296.

Rubia, K., Halari, R., Christakou, A., Taylor, E., 2009. Impulsiveness as a timing disturbance: neurocognitive abnormalities in attention-deficit hyperactivity disorder during temporal processes and normalization with methylphenidate. Philos. Trans. R. Soc. Lond. Series B Biol. Sci. 364 (1525), 1919-1931. https://doi.org/10.1098/rstb. 2009.0014.

Ruiz, E.J.C., del Consuelo Escoto Ponce de Leon, M., Diaz, J.M.M., 2008.

Neuropsychological evaluation in patients with eating disorders. Salud. Mental. 31 (6), 441-446.

Safer, D.L., Telch, C.F., Agras, W., 2001. Dialectical behavior therapy for bulimia nervosa. Am. J. Psychiatry 158 (4), 632-634.

Schachar, R., Logan, G.D., Robaey, P., Chen, S., Ickowicz, A., Barr, C., 2007. Restraint and cancellation: multiple inhibition deficits in attention deficit hyperactivity disorder. J. Abnorm. Child. Psychol. 35 (2), 229-238. https://doi.org/10.1007/s10802-0069075-2.

Serpell, L., Hirani, V., Willoughby, K., Neiderman, M., Lask, B., 2006. Personality or pathology? Obsessive-compulsive symptoms in children and adolescents with anorexia nervosa. Eur. Eat. Disord. Rev. 14 (6), 404-413. https://doi.org/10.1002/erv. 742.

Serpell, L., Livingstone, A., Neiderman, M., Lask, B., 2002. Anoreixa nervosa: obsessivecompulsive disorder, obsessive-compulsive personality disorder, or neither? Clin. Psychol. Rev. 22 (5), 647-669. https://doi.org/10.1016/S0272-7358(01)00112-X.

Shallice, T., 1982. Specific Impairments of Planning. Philos. Trans. R. Soc. Lond. Series B Biol. Sci. 298 (1089), 199-209. https://doi.org/10.1098/rstb.1982.0082.

Schaumberg, K., Zerwas, S., Goodman, E., Yilmaz, Z., Bulik, C.M., Micali, N., 2019. Anxiety disorder symptoms at age 10 predict eating disorder symptoms and diagnoses in adolescence. J. Child Psychol. Psychiatry 60 (6), 686-696.

Sherman, B.J., Savage, C.R., Eddy, K.T., Blais, M.A., Deckersbach, T., Jackson, S.C., Herzog, D.B., 2006. Strategic memory in adults with anorexia nervosa: are there similarities to obsessive compulsive spectrum disorders? Int. J. Eat. Disord. 39 (6), 468-476. https://doi.org/10.1002/eat.20300.

Shin, M.S., Park, S.Y., Park, S.R., Seol, S.H., Kwon, J.S., 2006. Clinical and empirical applications of the Rey-Osterrieth complex figure test. Nat. Protoc. 1 (2), 892-899. https://doi.org/10.1038/nprot.2006.115.

Southgate, L., Tchanturia, K., Treasure, J., 2008. Information processing bias in anorexia nervosa. Psychiatry Res 160 (2), 221-227.

Stedal, K., Dahlgren, C., 2015. Neuropsychological assessment in adolescents with anorexia nervosa - exploring the relationship between self-report and performance- based testing. Journal of Eating Disorders 27. https://doi.org/10.1186/s40337-0150062-2.

Steiger, H., Bruce, K., 2007. Phenotypes, endophenotypes, and genotypes in bulimia spectrum eating disorders. Can J Psychiatry 52 (4), 220-227. https://doi.org/10. $1177 / 070674370705200403$.

Steward, T., Mestre-Bach, G., Vintro-Alcaraz, C., Aguera, Z., Jimenez-Murcia, S., Granero, R., Fernandez-Aranda, F., 2017. Delay Discounting of Reward and Impulsivity in Eating Disorders: from Anorexia Nervosa to Binge Eating Disorder. Eur. Eat. Disord. Rev. 25 (6), 601-606. https://doi.org/10.1002/erv.2543.

Stroop, J.R., 1935. Studies of interference in serial verbal reactions. J. Exp. Psychol. 18, 643-662. https://doi.org/10.1037/H0054651.

Talbot, A., Hay, P., Buckett, G., \&Touyz, S., 2015. Cognitive deficits as an endophenotype for anorexia nervosa: an accepted fact or a need for re-examination? Int. J. Eat. Disord. 48 (1), 15-25. https://doi.org/10.1002/eat.22332.

Symmonds, M., Emmanuel, J., Drew, M., Batterham, R., Dolan, R., 2010. Metabolic State Alters Economic Decision Making under Risk in Humans. PLOS ONE. https://doi.org/ 10.1371/journal.pone.0011090.

Tchanturia, K., Davies, H., Roberts, M., Harrison, A., Nakazato, M., Schmidt, U., Morris, R., 2012a. Poor cognitive flexibility in eating disorders: examining the evidence using the Wisconsin Card Sorting Task. PLoS ONE [Electronic Resource] 71 (1). https://doi. org/10.1371/journal.pone.0028331.

Tchanturia, K., Harrison, A., Davies, H., Roberts, M., Oldershaw, A., Nakazato, M., Treasure, J., 2011. Cognitive flexibility and clinical severity in eating disorders. PLoS ONE 6 (6), e20462. https://doi.org/10.1371/journal.pone.0020462.

Tchanturia, K., Liao, P.C., Forcano, L., Fernandez-Aranda, F., Uher, R., Treasure, J., Campbell, I.C., 2012b. Poor decision making in male patients with anorexia nervosa. Eur. Eat. Disord. Rev. 20 (2), 169-173. https://doi.org/10.1002/erv.1154.

Tchanturia, K., Morris, G., Surguladze, S., Treasure, J., 2002. An examination of perceptual and cognitive set shifting tasks in acute anorexia nervosa and following recovery. Eat. Weight Disord.-Stud. Anorexia, Bulimia and Obesit 7 (4), 312-315. https://doi.org/10.1007/BF03324978.

Tchanturia, K., Serpell, L., Troop, N., Treasure, J., 2001. Perceptual illusions in eating disorders: rigid and fluctuating styles. J. Behav. Ther. Exp. Psychiatry 32 (3), 107-115. https://doi.org/10.1016/S0005-7916(01)00025-8.

Teti, G.L., Rebok, F., Rojas, S.M., Grendas, L., Daray, F.M., 2014. Systematic review of risk factors for suicide and suicide attempt among psychiatric patients in Latin America and Caribbean. Revista Panamericana de Salud Pública 36 (2), 124-133.

Touolopoulo, T., Rabe-Hesketh, S., King, H., Murray, R.M., Morris, G., 2003. Episodic memory in schizophrenic patients andtheir relatives. Schizophr. Res. 63 (3), 261-271. https://doi.org/10.1016/S0920-9964(02)00324-9.

Treasure, J., Lopez, C., Roberts, M., 2007. Endophenotypes in eating disorders: moving towards etiologically based diagnosis and treatment focused on pathophysiology. Ped. Health 1 (2), 171-181. https://doi.org/10.2217/17455111.1.2.171.

Tyagi, H., Patel, R., Rughooputh, F., Abrahams, H., Watson, A.J., Drummond, L., 2015. Comparative Prevalence of Eating Disorders in Obsessive-Compulsive Disorder and Other Anxiety Disorders. Psychiatry J. Print 2015, 186927. https://doi.org/10.1155/ 2015/186927.

Unterrainer, J.M., Owen, A.M., 2006. Planning and problem solving: from neuropsychology to functional neuroimaging. J. Physiol.-Paris 99 (4-6), 308-317. https://doi.org/10.1016/j.jphysparis.2006.03.014.

Uznadze, D.N., 1996. The Psychology of Set. Consultants Bureau.

Van den Eynde, F., Guillaume, S., Broadbent, H., Stahl, D., Campbell, I.C., Schmidt, U., Tchanturia, K., 2011. Neurocognition in bulimic eating disorders: a systematic review. Acta Psychiatr. Scand. 124 (2), 120-140. https://doi.org/10.1111/j.1600 0447.2011.01701.x.

Van den Eynde, F., Koskina, A., Syrad, H., Guillaume, S., Broadbent, H., Campbell, I., Schmidt, U., 2012a. State and trait food craving in people with bulimic eating disorders. Eat. Behav. 13 (4), 414-417. https://doi.org/10.1016/j.eatbeh.2012.07.007.

Van den Eynde, F., Samarawickrema, N., Kenyon, M., DeJong, H., Lavender, A., Startup H., Schmidt, U., 2012b. A study of neurocognition in bulimia nervosa and eating disorder not otherwise specified-bulimia type. J. Clin. Exp. Neuropsychol. 34 (1), 67-77. https://doi.org/10.1080/13803395.2011.621891.

Vitousek, K., Manke, F., 1994. Personality variables and disorders in anorexia nervosa and bulimia nervosa. J. Abnorm. Psychol. 103, 137-147. https://doi.org/10.1037/ 0021-843X.103.1.137.

Waxman, S.E., 2009. A systematic review of impulsivity in eating disorders. Eur. Eat. Disord. Rev. 17 (6), 408-425. https://doi.org/10.1002/erv.952.

Whiteside, S.P., Lynam, D.R., Miller, J.D., Reynolds, S.K., 2005. Validation of the UPPS impulsive behaviour scale: a four-factor model of impulsivity. Eur. J. Pers. 19 (7) 559-574. https://doi.org/10.1002/Per.556.

Wildes, J.E., Forbes, E.E., Marcus, M.D., 2014. Advancing research on cognitive flexibility in eating disorders: the importance of distinguishing attentional set-shifting and reversal learning. Int. J. Eat. Disord. 47 (3), 227-230. https://doi.org/10.1002/eat. 22243.

Wu, M., Hartmann, M., Skunde, M., Herzog, W., Friedrich, H.C., 2013. Inhibitory control in bulimic-type eating disorders: a systematic review and meta-analysis. PLoS ONE [Electronic Resource] 8 (12). https://doi.org/10.1371/journal.pone.0083412.

Zakzanis, K.K., Campbell, Z., Polsinelli, A., 2010. Quantitative evidence for distinct cognitive impairment in anorexia nervosa and bulimia nervosa. J. Neuropsychol. 4 (1), 89-106. https://doi.org/10.1348/174866409X459674. 